\title{
Effect of Tetraethoxy-silane (TEOS) Amounts on the Corrosion Prevention Properties of Siloxane-PMMA Hybrid Coatings on Galvanized Steel Substrates
}

\author{
Marielen Longhi ${ }^{a}$, Sandra Raquel Kunsta ${ }^{a}$, Lilian Vanessa Rossa Beltrami ${ }^{b}$, Estela Knopp Kerstner ${ }^{b}$, \\ Cícero Inácio Silva Filho ${ }^{c}$, Victor Hugo Vitorino Sarmento ${ }^{c}$, Célia Malfatti ${ }^{b}$ \\ aPrograma de Pós-Graduação em Engenharia de Processos e Tecnologia, Universidade de \\ Caxias do Sul-UCS, Rua Francisco Getúlio Vargas, 1130, CEP 95070-560, Caxias do Sul, RS, Brazil \\ ${ }^{b}$ Laboratório de Pesquisa em Corrosão, Universidade Federal do Rio Grande do Sul - UFRGS, \\ Avenida Bento Gonçalves, 9500, CEP 91501-970, Porto Alegre, RS, Brazil \\ ${ }^{c}$ Departamento de Química, Universidade Federal de Sergipe - UFS, \\ Avenida Vereador Olimpio Grande, s/n, Centro, CEP 49500-00, Itabaiana, SE, Brazil
}

Received: August 28, 2014; Revised: October 29, 2015

\begin{abstract}
Siloxane-poly(methyl methacrylate) (PMMA) organic-inorganic hybrid coatings were deposited on galvanized steel by the dip-coating sol-gel technique. Anticorrosion properties, as well as the morphological, surface and structural features were studied. Hybrid coatings were synthesized from tetraethoxy-silane (TEOS) and methyl methacrylate (MMA) as inorganic and organic phases, respectively, linked by 3-metacriloxypropyl-trimethoxysilane (TMSM) as a coupling agent. The MMA/TMSM ratio was kept constant, whereas the four TEOS/TMSM ratios were varied. The characterization of coatings was assessed using several techniques such as Scanning Electronic Microscopy (SEM), Contact Angle, Fourier Transform Infrared (FT-IR), Open Circuit Polarization (OCP), Atomic Force Microscopy (AFM) and Electrochemical Impedance Spectroscopy measurements (EIS). The EIS results, which were obtained for the hybrid coatings, were discussed based on an electrical equivalent circuit used to adjust the experimental data. The results showed that the increasing the TEOS content caused increase in coating thickness, increased in the surface roughness and increased in the surface hydrophobicity. The film with the highest TEOS content presented the best electrochemical performance, more effective in protecting against corrosion.
\end{abstract}

Keywords: galvanized steel, silane, hybrid coating, corrosion

\section{Introduction}

Hot-dip galvanizing technique has been in practice for over a century as it can protect steel products from atmospheric corrosion in an effective and economic way'. Moreover, the excellent anti-corrosive behavior of chromate films is well known. They have been used for many years to reduce the reactivity of zinc surfaces on galvanized steel. However, with the growing quest for environmental awareness, many studies are focused on the replacement of waste-producing and carcinogenic treatments, especially the process of phosphating and chromatization based on hexavalent chromium ${ }^{2}$.

In the last two decades, the potential of organofunctional silane coatings for the replacement of chrome conversion treatments has been the topic of a huge number of studies ${ }^{3-5}$. Silanes have been studied as coupling agents between inorganic and organic materials since the first works of Pluddemann ${ }^{6}$. Silanes are hybrid compounds which combine organic functional groups and an inorganic silicon base. Its general formula is R' $\left(\mathrm{CH}_{2}\right)_{n} \mathrm{Si}(\mathrm{OR})_{3}$ where $\mathrm{R}$ ' is an organofunctional group and $\mathrm{R}$ is a hydrolyzable alkoxy group. When in contact with water, the silanes are hydrolyzed to form silanol

*e-mail: lvrossa@yahoo.com.br groups $(\mathrm{SiOH})$ which allow the surface to connect to the metal hydrate (Metal-OH) via the formation of Si-O-metal. The silanol groups undergo a self-crosslinking process through siloxane bonds (Si-O-Si). As a result, the organic coating layer is chemically bonded to the metal substrate ${ }^{7}$. In regards to the corrosion science, a lot of effort has been made to apply these materials as adhesion promoters between metallic substrates and organic coatings used for protection against the corrosion phenomena ${ }^{8,9}$. The chemistry of silanes and the mechanism of interaction of these molecules with a metallic substrate and an organic coating has been widely explained. Silane films not only ensure the adhesion between metal substrates and organic coatings, but they also provide a thin, but efficient, barrier against the diffusion of oxygen to the metal interface ${ }^{8}$.

However, the silanes films described above do not offer the same satisfactory corrosion resistance as the traditional chromate film. Thus, in order to make these silane coatings more effective as a protection barrier to be used in zinc substrates, new types of materials have been developed. Blends of polymers ${ }^{8,9}$ and organic-inorganic hybrid materials ${ }^{10}$ are among the main types of studied materials. 
Organic-inorganic hybrids coatings have applications in many fields of materials chemistry because they are simple to process, and they can be used to obtain coatings to improve the corrosion resistance of some metallic substrates ${ }^{8-11}$.

The tetraethoxysilane (TEOS) is a commonly silane used to form films that protect the metal of the corrosive attack. According to several authors ${ }^{10,12-17}$ the TEOS based hybrids film forms an homogeneous, compact and resistant physical barrier. These hybrid films protect and assure the integrity of metal substrates in corrosive media.

The corrosion resistance provided by the coating applied on a metallic substrate depends on its barrier and adherence properties. Therefore, one possible way to enhance the corrosion protection promoted by the hybrid coating is by improving its degree of polymerization and its cross-linking nodes density ${ }^{8}$. Thus, the published results show that the use of the silane precursor 3-(trimethoxysilyl propyl) methacrylate (TMSPMA) - also known as 3-metacriloxy-propyl-trimethoxysilane (TMSM), on the composition of the hybrid coatings promotes a good linking between the organic and inorganic phases, preventing the separation of phases. Furthermore, the possibility to obtain thicker coatings, free of cracks, is due to the stability of poly (methyl methacrylate), PMMA, and due to the ease of polymerization of methacrylate groups (MMA), by UV radiation, or by thermal treatments which help to increase the refractive index ${ }^{18,19}$.

Among the current deposition technologies used for the application of these coatings, the dip-coating process has stood among the others due to its various advantages ${ }^{1,18}$.

In this context, the present work consists in studying galvanized steel coated with a siloxane-PMMA organic-inorganic hybrid film using the dip-coating process. These coatings were produced from the precursors tetraethoxy-silane (TEOS) and TMSM, modified with a metacrilate group (MMA), as coupling agent. The MMA/TMSM ratio was kept constant, whereas the four TEOS/TMSM ratios were varied. Anticorrosion properties of organic-inorganic hybrid coatings were investigated using classical electrochemical techniques, after different periods of immersion in a $0.05 \mathrm{~mol} . \mathrm{L}^{-1} \mathrm{NaCl}$ solution. Morphological characterization and coating thickness measurements were performed by scanning electron microscopy (SEM) and atomic force microscopy (AFM). Moreover, the coatings were evaluated concerning the wettability (contact angle determination) and the Fourier transform infrared (FTIR) spectra for all the hybrid films.

\section{Experimental Procedures}

All chemicals which were used were commercially available. The Tetraethoxy-silane (TEOS - (Aldrich), 3-Methacryloxypropyl-trimethoxysilane (TMSM, Fluka), Ethanol (Mallinckrodt) were used as received. The Methyl methacrylate, (MMA, Fluka) was distilled to remove the polymerization inhibitor (hydroquinone) and stored in a freezer prior to use. The Benzoyl peroxide, BPO (Reagen), was re-crystallized from ethyl alcohol.

The hybrid coatings from the sol-gel reactions were performed as follows: TEOS, TMSM, acidified water $\left(\mathrm{HNO}_{3}\right.$ at $\left.\mathrm{pH}=1\right)$ and ethanol were mixed and stirred together for 1 hour at $60{ }^{\circ} \mathrm{C}$. In a separate recipient, MMA and BPO were mixed and stirred, at room temperature, until the complete homogenization of BPO was achieved. The contents of the two recipients were then mixed and stirred for 5 minutes, forming a transparent hybrid sol. The hybrid sol used in the coatings was prepared using the following molar ratios: (TEOS:MPTS):MMA = 1:6; H2O: $($ TEOS:MPTS) = 3.5:1; ethanol: $\mathrm{H} 2 \mathrm{O}=1: 2 ; \mathrm{BPO}: \mathrm{MMA}=1: 100$. In order to determine the effect of the inorganic phase on the structural features and on the corrosion protection of hybrid coatings, the samples were prepared using four different TEOS and TMSM ratios, designated T0, T1, T2 and T3, whereas the TEOS:TMSM ratio of each sample was 1, 2, 3 and 4 respectively.

The hybrid sols were deposited by dip coating onto plates of galvanized steel $(4 \times 2 \mathrm{~cm})$, composed as follows: $\left(\mathrm{wt}_{\text {max. }} \%\right.$ ) of $0.15(\mathrm{C}), 0.6(\mathrm{Mn}), 0.04(\mathrm{~S}), 0.04(\mathrm{P})$ with the balance consisting of $\mathrm{Zn}$. In order to clean the surface for deposition, the galvanized steel samples were rinsed with ethyl alcohol and dried under a hot air stream. They were then degreased with neutral detergent at $70{ }^{\circ} \mathrm{C}$ by immersion for 10 minutes, then rinsed further with deionized water and ethyl alcohol and finally dried under a hot air stream. After, the samples were dipped in the sol, withdrawn at a rate of $14 \mathrm{~cm} \cdot \mathrm{min}^{-1}$, and air-dried for approximately 10 minutes. This procedure was performed three times, after which the coated substrates were heated at $60{ }^{\circ} \mathrm{C}$ for 24 hours and cured at $160^{\circ} \mathrm{C}$ for $3 \mathrm{~h}$. This procedure favors the breakdown of the BPO and the production of free radicals, leading to copolymerization of the MMA, for PMMA, and of the MPTS methacrylic groups and to the densification of the gel network. Figure 1 shows a flowchart of the formulation and implementation of the hybrid film.

The morphology, topography and wettability of the coated surfaces were monitored, respectively, by SEM, AFM and Contact Angle. The SEM micrographs were acquired in a JEOL 6060 with an acceleration voltage of $20 \mathrm{keV}$. Samples were analyzed from a top view for the superficial morphology identification as well by cross section to determine the thickness of the silane layer. AFM images were obtained using a SHIMADZU SPM $9600 \mathrm{~J} 3 \circledR$ device and acquired obtained in the dynamic mode, with a roughness of less than $5 \mu \mathrm{m}$, with $30 \mu \mathrm{m}$ sweep aside.

The Contact Angle measurements were performed by the sessile drop method in equipment developed by the Laboratory of Optic and Laser of Physics Institute (IF) of UFRGS. The images were analyzed by software which has also been developed by the IF. Water was used as the fluid in this research. It is known that silane films have hydrophobic character when sufficiently cross-linked (cross-linking). Thus, the contact angle of a good cross-linked film is approximately 90 degrees of order. However, this value becomes smaller after immersion in an aqueous solution, indicating that the Si-O-Si groups are not stable. Then, due to the fact that these links are not stable Si-O-Si groups can undergo hydrolysis reactions, forming once again hydrophilic $\mathrm{Si}-\mathrm{OH}$ groups in a way that water and ions can penetrate and react with the interface ${ }^{20}$. Consequently, the silane films temporarily protect the metal, and the film is even more hydrophobic because the barrier and adhesion properties can vary with the time of air or aqueous exposure due to the susceptibility of the $\mathrm{Si}-\mathrm{O}-\mathrm{Si}$ bonds to undergo reactions hydrolysis ${ }^{21}$. 


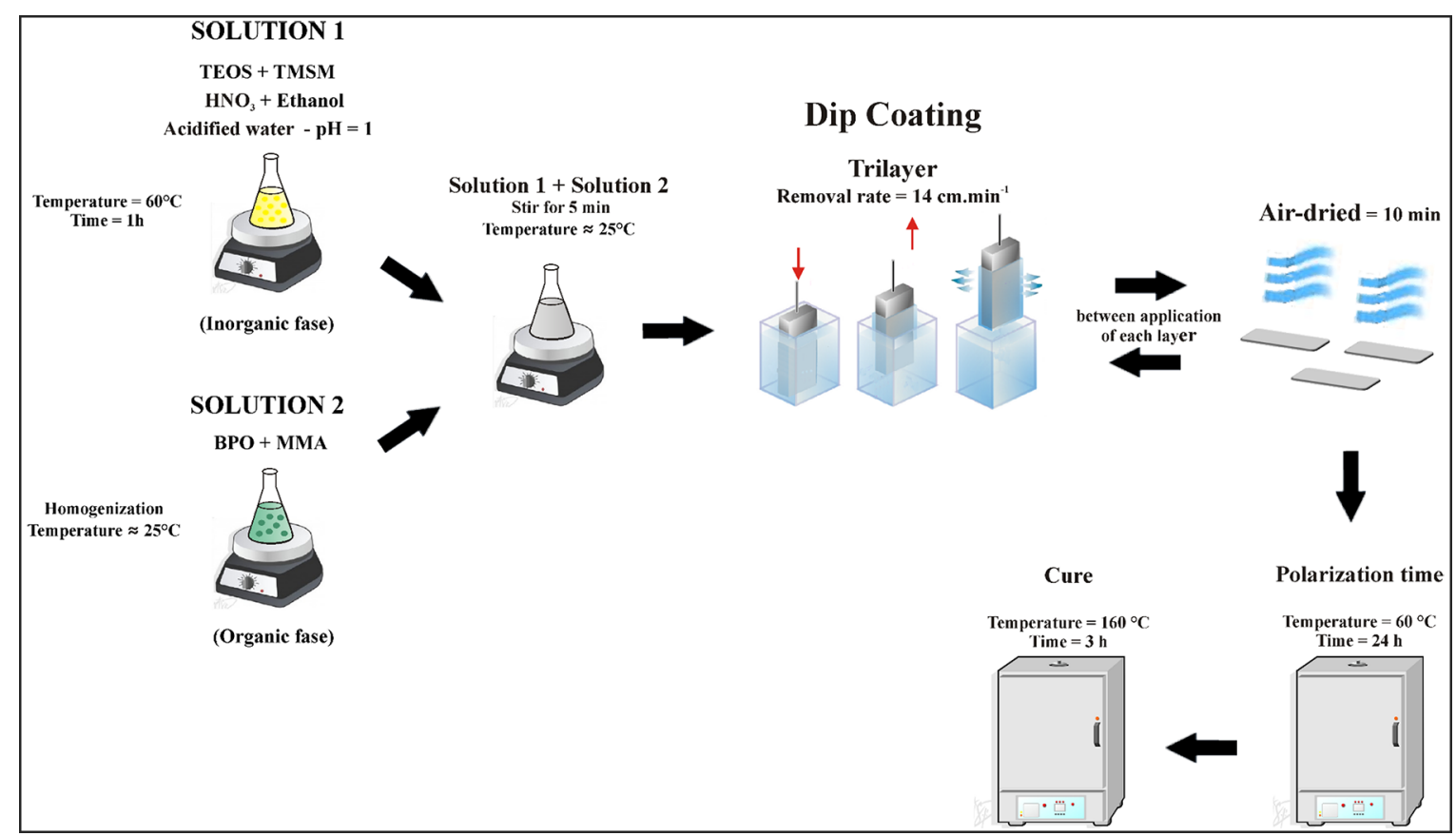

Figure 1. Schematic representation of the coating elaboration.

Since thin coatings cannot be directly used with the Fourier Transform Infrared (FT-IR), the films were prepared in petri dishes, at the same conditions of heating and curing, and then triturated. The spectra of the obtained powders were recorded on a Spectrometer using $\mathrm{KBr}$ pellets containing $1 \mathrm{mg}$ of sample. The FT-IR spectra were measured on a Perkin Elmer 1600 series FTIR spectrophotometer.

The corrosion performance of the coatings was evaluated by open circuit potential (OCP) monitoring, potentiodynamic polarization, and electrochemical impedance spectroscopy (EIS) measurements (Bode diagrams) in a 0.05 mol.L $\mathrm{L}^{-1} \mathrm{NaCl}$ solution, with $\mathrm{pH} 5.5$. This concentration is sufficiently high to activate the corrosion for relatively short exposure times, but low enough to enable the discernment of the effect of the different acids. Kozhukharov et al. ${ }^{22}$ also used 0.05 mol. $\mathrm{L}^{-1} \mathrm{NaCl}$ as a low enough concentration to allow the observation of inhibitors effects. The tests were performed in triplicate.

A potentiostat/galvanostat Omnimetra MOD. PG- 05 and a three-electrode cell were used to perform the analysis, with a platinum wire as a counter-electrode and a saturated calomel electrode (SCE) as the reference electrode (Figure 2). The area of the working electrode was $0.626 \mathrm{~cm}^{2}$. The polarization curves were collected at a scan rate of $1 \mathrm{mVs}^{-1}$ in a potential interval between $200 \mathrm{mV}$ (below OCP) and $1000 \mathrm{mV}$ (above $\mathrm{OCP}$ ). For the EIS measurements the systems were monitored for 96 hours. The amplitude of the EIS perturbation signal was $10 \mathrm{mV}$. The applied frequency range was from $100 \mathrm{kHz}$ to $10 \mathrm{mHz}$ using a Solartron 1255 and a potentiostat PAR273 frequency response analyzer. For the quantitative analysis, the results for the systems that presented the best anticorrosion performance were fitted using electrical equivalent circuits (EEC) with the Z-View ${ }^{\circledR}$ program. The consistency of the experimental data was verified with the Kramers-Kronig

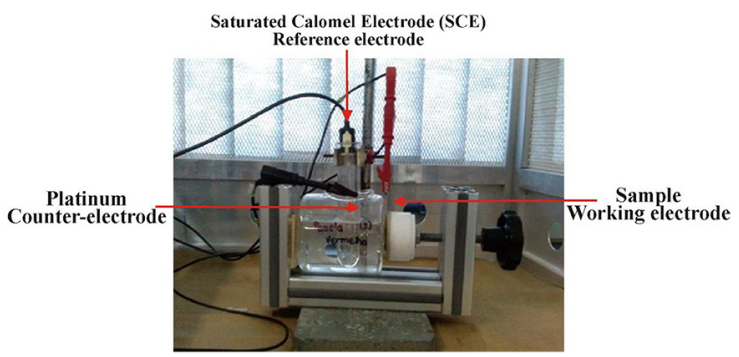

Figure 2. Electrochemical cell with three electrodes used in electrochemical characterizations.

transform, and those that did not match the pattem were removed.

The tribologic wear assays were performed with a tribometer, computer-controlled, with the ball-on-plate configuration (Figure 3 ). The wear test was conducted with a reciprocal linear movement whit aluminum sphere with a diameter $7.75 \mathrm{~mm}$. A constant force of $1.5 \mathrm{~N}$, a frequency of $2 \mathrm{~Hz}$ and track length of $2 \mathrm{~mm}$ were used.

\section{Results and Discussion}

\subsection{Structural features}

Figure 4 presents the SEM micrographs of several proportions obtained for hybrids coatings on galvanized steel, and indicate the influence of TEOS content (from T0 to T3) on the coating morphology. The T0 sample showed some cracks and heterogeneities, while in the $\mathrm{T} 1$ sample there were also some cracks in the layer, with some discontinuities. However the surface was homogeneous. For the T2 coating a homogeneous silane layer can be observed, with only a few cracks and a few discontinuities. Finally, the T3 sample 
did not present cracks, but a heterogeneous layer with an even coverage was formed.

Considering that the pretreatment that was applied, as well as the curing process, which were the same for all of the samples, these results suggest that the sol composition influences the silane coating formation. The increase of the TEOS/TMSM ratio (T2 and T3) promoted a more even coverage, even though the morphological features revealed some heterogeneities (T3).

Layer thickness was also determined by the SEM analysis using the cross-section view (Figure 5). The results are shown in Table 1. From the results it can be verified that the increase in the TEOS/TMSM ratio leads to an increase in the layer thickness, being T3 the thickest layer. This can be explained by the increase of the silicon content, which influences the coatings thickness, due to the increase in the percentage of the inorganic phase (siloxane) of the system (increase of TEOS). Besides, a higher densification of this film was observed ${ }^{23}$. This is due to the covalent bonds of the organic and inorganic precursors, which demonstrates

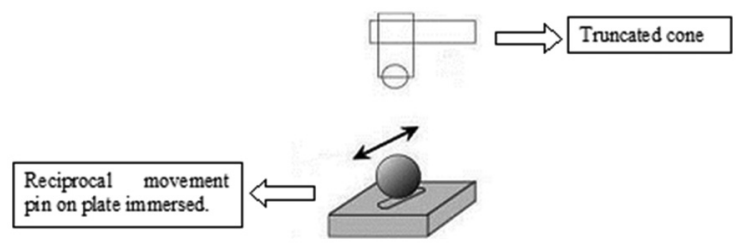

Figure 3. Schematic representation of the tribologic test system.
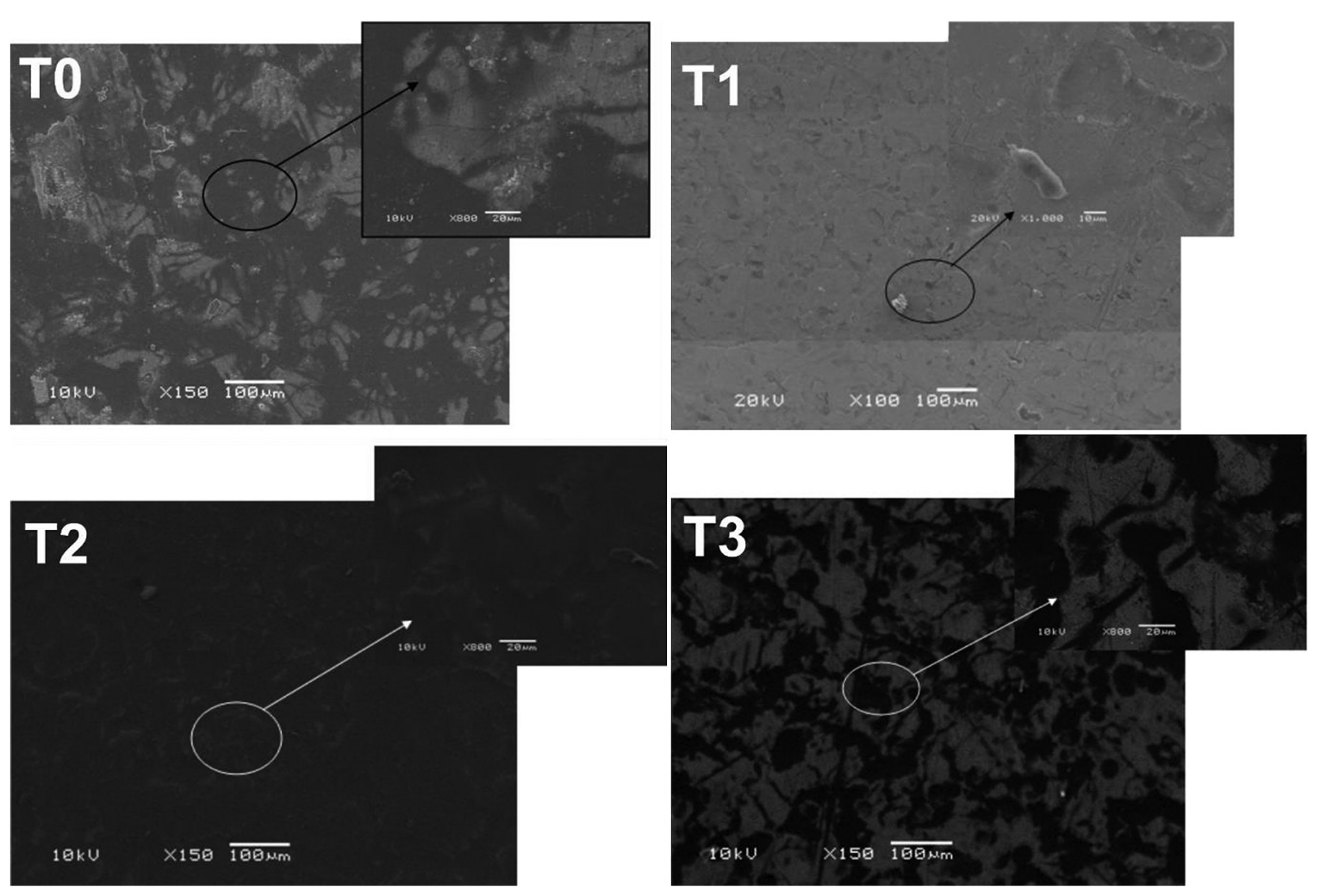

Figure 4. Micrographs obtained from SEM for siloxane-PMMA hybrid coatings with different TEOS ratios (T0, T1, T2 and T3), obtained on galvanized steel.

the synergistic effect of TMSM and TEOS precursors in the hybrid film.

In all hybrid films (T0, T1, T2 and T3), the MMA monomer was mixed to TMSM in order to increase the compactness of the structure of this layer by polymerization of the acrylate groups and their cross-linking with the silicon network. However, the T0 sample showed a relatively higher thickness than the other samples. This could be associated to the higher content levels of MMA, due to the fact that the MMA increases the polymeric chains of the film. The MMA monomer contains only one possible polymerization site per molecule; therefore, during the curing process, each monomer can only have one covalent bond with the TMSM, which, in its turn, has three hydrolyzable groups. Zaioncz et al. ${ }^{24}$ reported that the copolymerization of TMSM with MMA monomers gives rise to a cross-linked hybrid compound with the PMMA chains surrounding the siloxane particles. This results in a hybrid structure where the MMA radical, covalently bonded to the TMSM moieties through polymerization reactions,can only interact by weak Van der Waals forces ${ }^{25}$. This process

Table 1. Thickness of the resulting siloxane-PMMA hybrid coatings.

\begin{tabular}{ccc}
\hline Sample & Thickness $(\boldsymbol{\mu m})$ & $\begin{array}{c}\text { Standard deviation } \\
(\boldsymbol{\mu m})\end{array}$ \\
\hline T0 & 2.88 & \pm 0.42 \\
T1 & 1.58 & \pm 0.18 \\
T2 & 1.85 & \pm 0.16 \\
T3 & 5.63 & \pm 0.33 \\
\hline
\end{tabular}




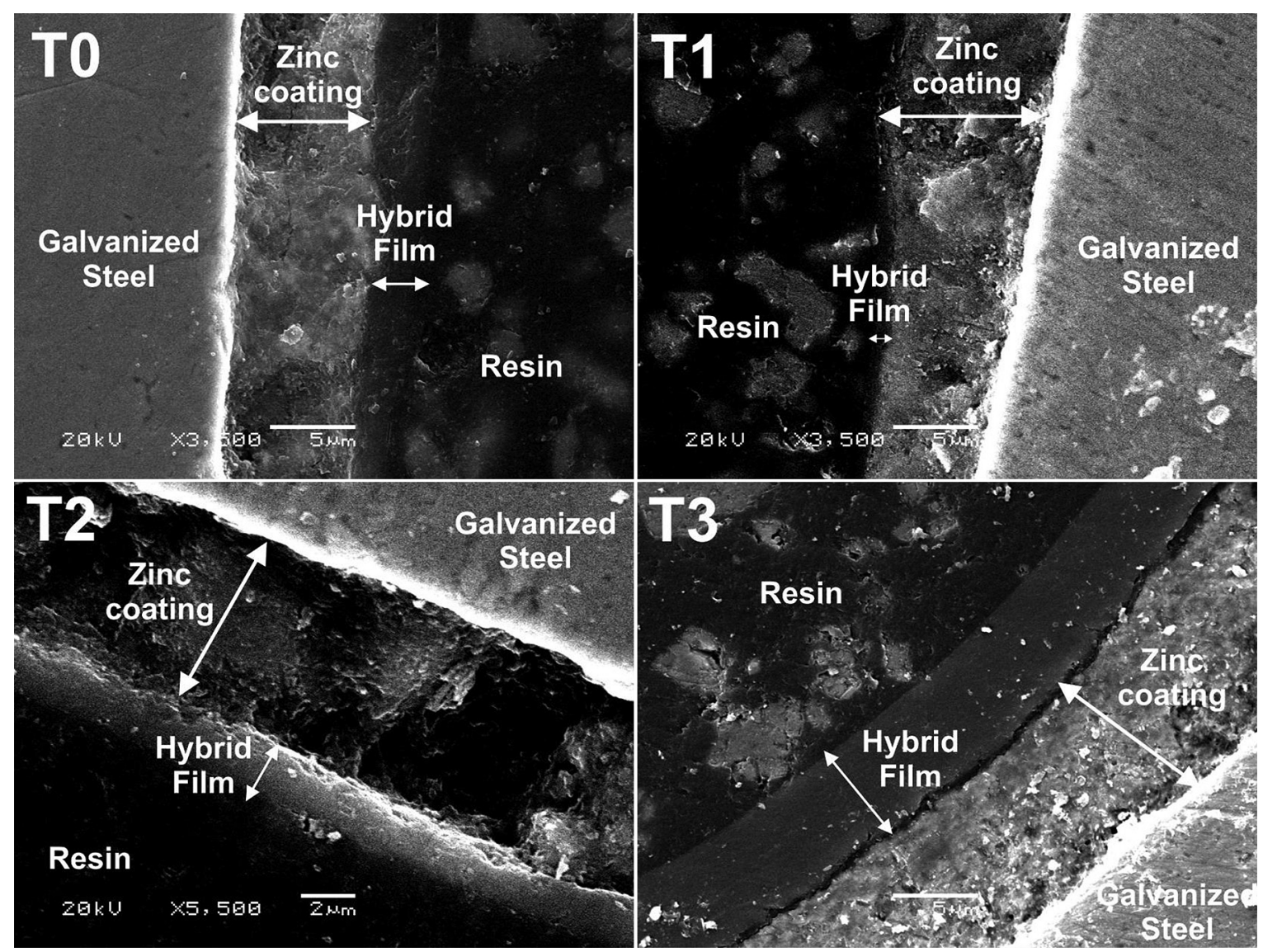

Figure 5. SEM micrographs (cross-section) of the siloxane-PMMA hybrid coatings.

could explain the lower thickness of the hybrid film which does not contain TEOS (T1).

The T1 and T2 systems showed lower layer thickness values possibly due to the insufficient TEOS/TMSM levels, thus not enabling the inorganic phase (siloxane) to be formed with a higher volume. Besides, the MMA content was also reduced, hence decreasing the polymeric phase content in the coatings.

These results are in agreement with some researchers ${ }^{26,27}$ who report that at higher temperatures, or whit the addition of a higher number of layers, an improved system in corrosion resistance can be achieved. However, the morphological analysis reveals the existence of microcracks systems for the T0, T1 and T2 samples, due to the fragility of thicker layers, and hence a decrease in corrosion resistance can be seen. Additionally, it is generally accepted that the cracked microstructure of the largest number of layers hybrid films is due to the drying stage ${ }^{28}$, because of the introduction of compressive stress during the cross-linking of the silane layer in the curing step $^{29}$.

Figure 6 displays the AFM 3-D images of the studied systems from a $70 \times 70 \mu \mathrm{m}^{2}$ area whereas the roughness values are summarized in Table 2. Firstly, the roughness values presented by the hybrid coatings were lower than the ones obtained for the uncoated galvanized steel sample, and there was a complete coverage of the metal substrate in the proposed coating. Besides, some spots with higher heights can be observed, which are probably related to the formation of acrylate clusters (white spots). As it can also be observed, the coatings with higher roughness values were obtained with lower TEOS / TMSM ratios (T0 and T1). Thus, the analysis of Figure 5a, b shows the appearance of a dark region, due to differences in the chemical composition of the highlighted region ${ }^{25}$.

This may be associated with the fact that the T0 and T1 sample containing contain a larger amount of MMA in the film, making it irregular. During the curing process, non-polymerized MMA can volatilize, creating tensioned regions and resulting in thinner films. This phenomenon can be observed in the lower layer thickness and in the creation of defective areas. Still, it is possible to observe that the hybrid films presented decreased roughness values in comparison to uncoated galvanized steel (Figure 6, Table 2).

The T3 sample was more irregular on the entire surface but with minor peaks. This can be associated with the composition formulation. The T3 sample, in this regard, has a greater amount of TEOS. This is due to the formation of a complete porous ceramic structure, which is heterogeneities ${ }^{30}$, after TEOS hydrolysis and cross-linking. Thus, the TEOS addition contributed to the irregular coverage observed.

From the results shown in Table 3 , a decrease in the contact angle can be observed for all studied systems related to the galvanized steel samples without a hybrid coating (GS), except for the T0 sample. This behavior indicates 

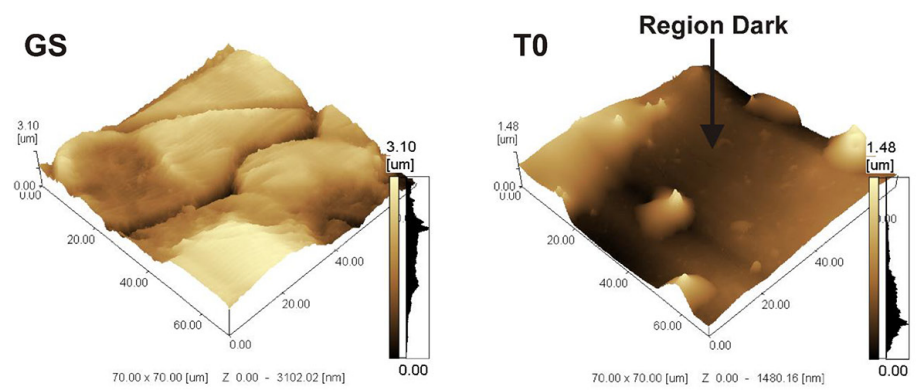

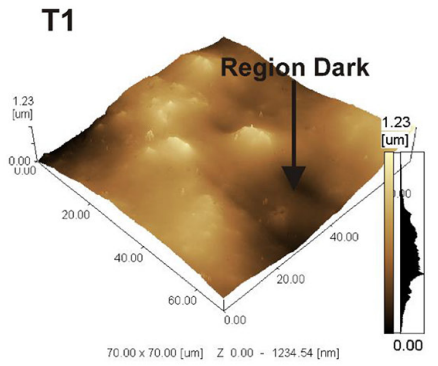

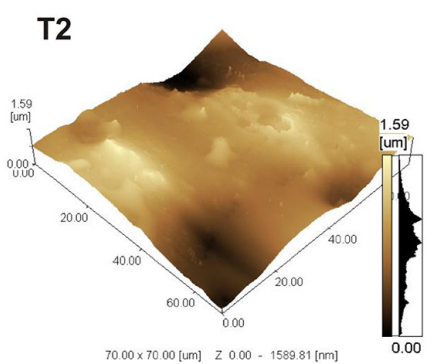

Figure 6. 3D AFM height of the systems.

Table 2. Roughness of the obtained siloxane-PMMA hybrid coatings.

\begin{tabular}{cccc}
\hline & \multicolumn{3}{c}{ AFM roughness } \\
\cline { 2 - 4 } Samples & $\mathbf{R a}(\boldsymbol{\mu m})$ & $\mathbf{R m s}(\boldsymbol{\mu m})$ & $\begin{array}{c}\text { Peak to peak } \\
(\boldsymbol{\mu m})\end{array}$ \\
\hline GS & $4.9 \pm 0.05$ & $5.97 \pm 0.11$ & $5.64 \pm 0.09$ \\
T0 & $0.54 \pm 0.05$ & $0.72 \pm 0.04$ & $1.48 \pm 0.06$ \\
T1 & $0.48 \pm 0.08$ & $0.61 \pm 0.07$ & $1.23 \pm 0.05$ \\
T2 & $0.35 \pm 0.09$ & $0.45 \pm 0.06$ & $1.59 \pm 0.07$ \\
T3 & $0.25 \pm 0.07$ & $0.31 \pm 0.04$ & $0.87 \pm 0.04$ \\
\hline
\end{tabular}

Table 3. Contact angle values obtained by the sessile drop method.

\begin{tabular}{cc}
\hline Sample & Contact Angle \\
\hline T0 & $87 \pm 0.35$ \\
T1 & $62 \pm 0.54$ \\
T2 & $62 \pm 1.54$ \\
T3 & $81 \pm 0.81$ \\
GS & $70 \pm 0.74$ \\
\hline
\end{tabular}

that the coatings which was obtained does not reduce the surface wettability. This can be associated to the hydrophilic behavior of the TEOS precursor. Furthermore, the T0 system, without the addition of TEOS, showed the highest contact angle value among the studied systems, and consequently, the lowest wettability. Besides, this film showed the highest wet ability (lowest contact angle values), among the studied samples. This behavior can be associated to a hydrophilic character introduced by the lower amount (concentration) of TEOS addition, providing non-hydrolyzed Si-OH groups and also discontinuities present in this film as noted in the AFM analysis (Figure 6 and Table 2). Thus, the non-hydrolyzed ester and hydrophilic $\mathrm{OH}$ groups are present. These ester and $\mathrm{OH}$ groups favor the water uptake, while the siloxane groups can be hydrolyzed when the films are exposed to the

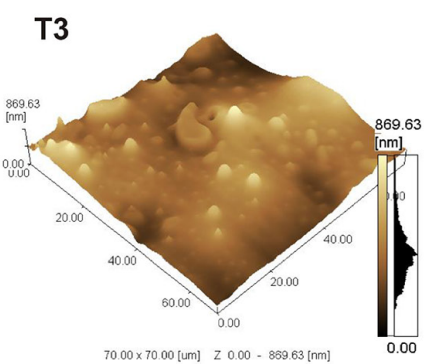

electrolyte, further increasing the number of hydrophilic $\mathrm{OH}$ groups in the film ${ }^{12}$.

However, when there is a perfect synergistic effect in the formulation, there is a greater formation of covalent bonds, and consequently, a greater cross-linking and a greater hydrophobicity of the system, as depicted in the T3 sample. Besides during the curing process, hydrophobic siloxane bonds are formed in the film network, which hinder water penetration $^{31}$.

Figure 7 and Table 4 shows the FT-IR spectra obtained for all of the reviewed coatings. Between $3360 \mathrm{~cm}^{-1}$ and $3620 \mathrm{~cm}^{-1}$ the broad band absorption is characteristic of the axial deformation of the $\mathrm{OH}(\mathrm{Si}-\mathrm{OH})$, which was not crosslinked in the curing process ${ }^{24}$. In this case, the band is more intense for the T2 sample, which suggests a greater amount of hydrophilic groups. This indicates that during the curing process, hydrophobic siloxane bonds are formed in the coating network, which hinders the penetration of wate $^{32}$. However, neither the precursor hydrolysis nor the cross-linking (polycondensation) is complete during the curing. Thus, non-hydrolyzed ester and hydrophilic $\mathrm{OH}$ groups are present in the coating structures. These groups, ester and $\mathrm{OH}$, favor water uptake, while the former group, siloxane, can be hydrolyzed when the coatings are exposed to the electrolyte further increasing the number of hydrophilic $\mathrm{OH}$ groups in the coating structure. This result is in agreement with the analysis of the contact angle (Table 3 ).

Around $1153 \mathrm{~cm}^{-1}$ there is a strong band corresponding to the stretching of the Si-O-Si (Table 4) which has been cross-linked during the curing process. The formation of the Si-O-Si layer exerts a protective effect on the substrate of galvanized steel. The band is slightly more intense for the T3 sample, which suggests a better condition of hydrolysis and subsequent crosslinking. This indicates that the sample showed a more complete hydrolysis of the silane precursors, as it can be seen in the contact angle results, where, indeed, this sample showed lower wettability values (Table 3 ). 
Moreover, this demonstrates the synergistic effect of the TMSM and TEOS precursors present in the hybrid coating.

The T0 and T1 samples did not showed many hydrophilic groups (peak at around $3360 \mathrm{~cm}^{-1}$ to $3620 \mathrm{~cm}^{-1}$, according to Figure 7), however this sample presented a peak which was similar to the T2 sample, which refers to the number of Si-O-Si groups (protective effect). This could be explained by the fact that the T0 and T1 (in the absence of TEOS and/or with a small amount of TEOS) the MMA radical is covalently bonded to the TMSM moieties through polymerization reactions and can only interact by weak Van der Waals forces. Taking into account these structural considerations, the coating thickness is expected to be lower due to the weak bonds (Figure 6 and Table 1). The silane coatings present a hydrophobic character when sufficiently cross-linked. Thus, the contact angle of a well cross-linked coating is on the order of approximately $90^{\circ}$. However, this value becomes smaller after the immersion in an aqueous solution, indicating that the Si-O-Si bond is not stable ${ }^{21}$. Then, due to the fact that these links are not stable, the $\mathrm{Si}-\mathrm{O}-\mathrm{Si}$ reactions can suffer hydrolysis, forming the $\mathrm{Si}-\mathrm{OH}$ hydrophilic groups again, allowing for water and ions to penetrate and react with the interface ${ }^{20}$. Consequently, the silane coatings temporarily protect metals even more than the hydrophobic coatings, since the barrier and adhesion properties can vary with the time of air or aqueous exposure, due to the susceptibility of the Si-O-Si to suffer from hydrolysis reactions.

Around the $2900 \mathrm{~cm}^{-1}$ band a peak was identified and associated to the $\mathrm{C}-\mathrm{H}\left(\mathrm{CH}_{2}\right.$ and $\left.\mathrm{CH}_{3}\right)$ symmetrical and

Table 4. FT-IR, peak assignment in relation to peak position.

\begin{tabular}{cl}
\hline $\begin{array}{c}\text { Peak position } \\
\left(\mathbf{c m}^{-1}\right)\end{array}$ & \multicolumn{1}{c}{ Peak assignment } \\
\hline $600-700$ & $\mathrm{C}-\mathrm{H}\left(\mathrm{Si}-\mathrm{CH}_{2}-\mathrm{CH}_{2}-\mathrm{Si}\right)$ stretching \\
$1000-1200$ & $\mathrm{Si}-\mathrm{O}-\mathrm{Si}$ crosslinked $\mathrm{Si}-\mathrm{O}$ stretching \\
$1300-1400$ & $\mathrm{CH}_{2}$ and $\mathrm{CH}_{3}$ scissoring \\
$1600-1670$ & $\mathrm{C}=\mathrm{C}-\mathrm{H}_{2}$ axial deformation \\
$1700-1750$ & $\mathrm{C}=\mathrm{O}$ axial deformation \\
$2900-3000$ & $\mathrm{C}-\mathrm{H}\left(\mathrm{CH}_{2}\right.$ e $\left.\mathrm{CH}_{3}\right)$ symmetric and asymmetric \\
& stretching \\
$3200-3700$ & Si-OH axial deformation \\
\hline
\end{tabular}

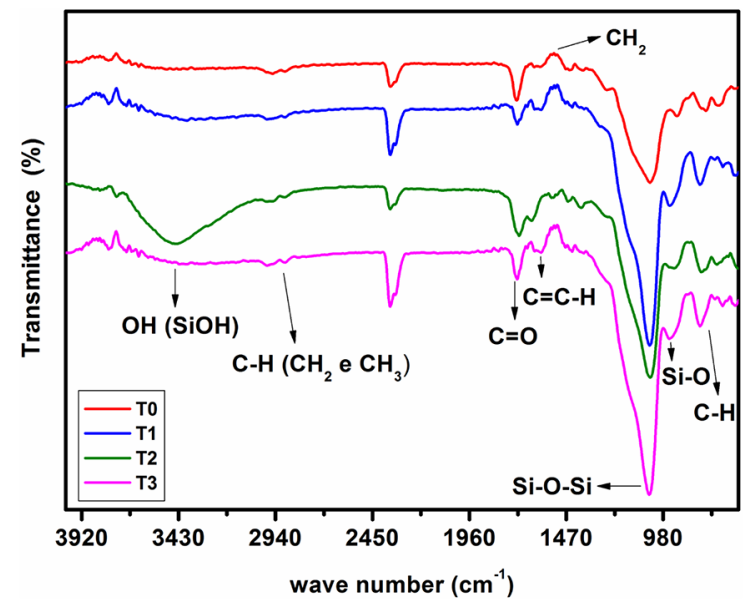

Figure 7. FT-IR spectra of the hybrid coatings. asymmetrical stretching. The bands around 1728 and $1622 \mathrm{~cm}^{-1}$ are associated to the stretching vibrations of the $\mathrm{C}=\mathrm{O}$ and $\mathrm{C}=\mathrm{C}$ groups respectively.

The silylation process can be described as a three-step reaction model. In the first step, the Si-OR groups turn into $\mathrm{Si}-\mathrm{OH}$ through hydrolysis reaction (Scheme 1); subsequently, the $\mathrm{Si}-\mathrm{OH}$ groups turn into oligomeric siloxane containing some unreacted $\mathrm{Si} \mathrm{OH}$ by condensation reaction (Scheme 2); Lastly, the Si-OH groups in the siloxane form hydrogen bonds with thehydroxyl groups on the galvanized steel foil surface, then $\mathrm{Si} \mathrm{OH}$ groups form covalent bonds with galvanized steel foil through condensation during a heating process ${ }^{33}$.

\subsection{Corrosion analysis}

Open circuit potential (OCP) measurements were performed with the intent to monitor the dependence potential immersion time, in 0.05 mol. $\mathrm{L}^{-1} \mathrm{NaCl}$ solution, as illustrated in Figure 8.

With the analysis of the OCP values for the hybrid coatings which were studied (Figure 8), it was possible to observed that the silane coated samples showed potential values that shifted toward less active potentials in relation to the galvanized steel without a silane coating. This means that the hybrid coatings promoted the formation of a barrier between the substrate and the electrolyte. However, it was not possible to observe a significant difference in the OCP values for the studied systems.

The OCP values for the samples covered with the hybrid films (T0, T1, T2 and T3), show that the potentials were less active than for the uncoated galvanized steel (HDG). This means that the hybrid films promoted the formation of a barrier between the substrate and the solution. Previous results reported in the literature show that hybrid films confer a higher anti-corrosion resistance than silane films ${ }^{34,35}$. Furthermore, the hybrid films that were studied constitute a class II hybrid, where organic and inorganic precursors are linked by covalent bonds ${ }^{36}$.

In Figure 9 the Bode diagrams for all of the hybrid siloxane-PMMA coatings studied and for the galvanized steel without treatment are shown, within 24 hours (Figure 9a) and 72 hours (Figure 9b), and an immersion in 0.05 mol. $\mathrm{L}^{-1} \mathrm{NaCl}$. In the first 24 hours of immersion, the T2 and T3 samples showed a phenomenon associated with the high frequency barrier effect of the hybrid coating, indicating a better corrosion performance. Such behavior may be associated with the morphology of the coatings, considering that both systems showed the formation of crack-free coatings. This good performance is confirmed by the high values shown by the impedance module (Figure 9b), since both hybrid coatings presented higher values, in comparison to the other samples.

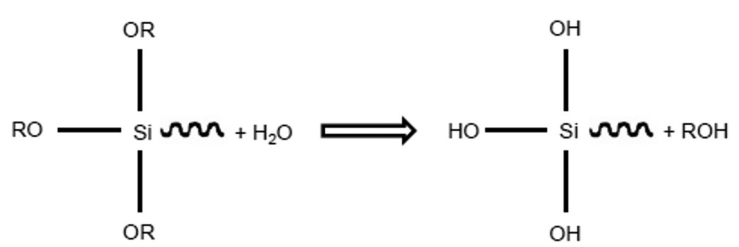

Scheme 1. Si-OR groups turn into $\mathrm{Si}-\mathrm{OH}$ through hydrolysis reaction. 


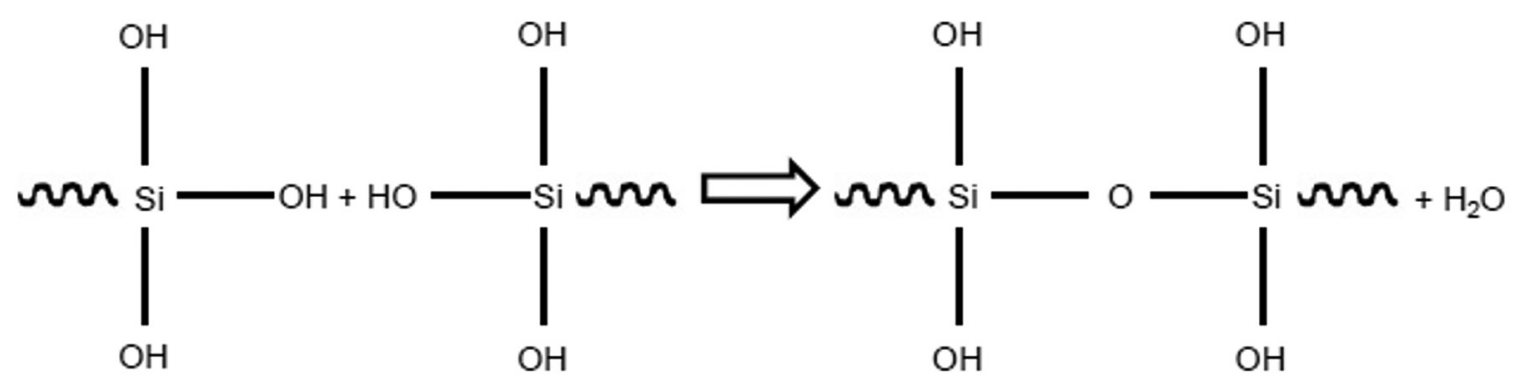

Scheme 2. Si-OH groups turn into oligomeric siloxane containing some unreacted $\mathrm{Si} \mathrm{OH}$ by condensation reaction.

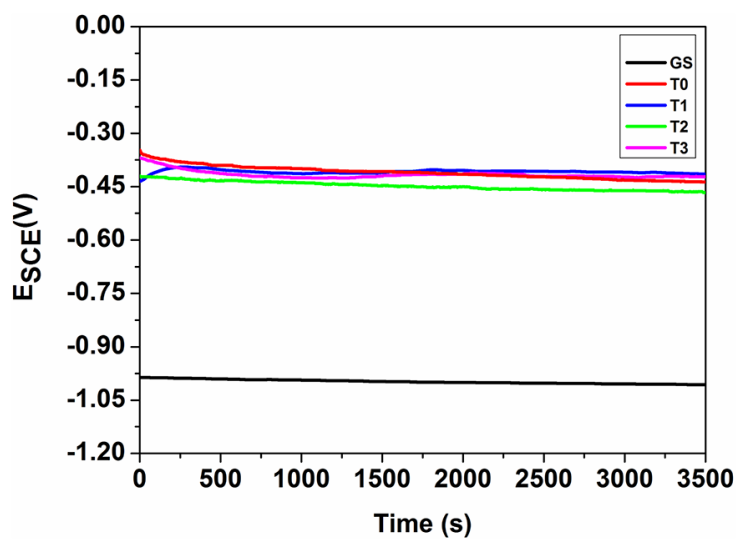

Figure 8. Open-circuit potential $\left(\mathrm{E}_{\mathrm{OC}}\right)$ measurements in a 0.05 mol. $\mathrm{L}^{-1} \mathrm{NaCl}$ solution.

After 72 hours of immersion in $\mathrm{NaCl} 0.05 \mathrm{M}$ (Figure 9b), the high frequency phenomenon remains clear only for the T3 sample, though not as well defined as on the lower immersion times. In contrast, for the T1 and T2 samples such phenomenon is evident in middle frequencies, and for the T0 and GS samples it is shifted towards lower frequencies. This shift is probably associated with the formation of corrosion products originating from the zinc coating, thus demonstrating the barely protective character of the T0 system, since at the end of 72 hours of immersion it has a similar behavior to the uncoated galvanized steel, indicating that electrochemically active species reach the electrode surface more easily. Accordingly, the charge transfer resistance also decreased, pointing to faster interfacial electrochemical processes $^{37}$.

The impendance module of the T3 sample remained higher, showing that this coating has the best performance in relation to corrosion, comparing with the other coatings and to the galvanized steel.

The EIS was used in the present work to characterize the corrosion behavior of the developed coatings. A more detailed interpretation of the EIS measurements was performed by fitting the experimental plots using equivalent electrical circuit models, which were proposed to simulate the electrochemical behavior of the studied coatings (Tables 5-8). These models were based on the combination of resistances, capacitances, and other elements that should have a physical meaning, related to the electrochemical response of the system.
Tables 5-8 present the electrical parameter values obtained by fitting the equivalent electrical circuit from the experimental EIS data, obtained for the T0, T1, T2 and T3 hybrid coatings for 96 hours of immersion in a 0.05 mol. $\mathrm{L}^{-1} \mathrm{NaCl}$ solution. These results are related to the interaction of the electrolyte with the coating, such as its permeation through the coating, which is not an instantaneous process. Other authors ${ }^{22,31}$ have found the same results and only present EIS data after some hours of immersion.

In several circuits the capacitance was substituted by a CPE in order to take into account the non-ideality of the systems. A value of $n=1$ corresponds to a smooth surface; therefore, in this case, the CPE should be substituted by an ideal capacitor $C$. In these circuits (Tables 5-8), $\mathrm{R}_{\mathrm{S}}$ represents the electrolyte resistance, $\mathrm{R}_{\mathrm{HF}}$ and $\mathrm{CPE}_{\mathrm{HF}}$ represent, respectively, the resistance and a constant phase element associated to the barrier effect of the hybrid film. In the same circuit, $\mathrm{R}_{\mathrm{Ox}}$ and $\mathrm{CPE}_{\mathrm{Ox}}$ represent the resistance and a constant phase element, indicating an acceleration of the interfacial process associated with the zinc oxide on the substrate surface. $\mathrm{R}_{\mathrm{CT}}$ and $\mathrm{CPE}_{\mathrm{CT}}$ were added and represent, respectively, the charge transfer resistance to the metal. As reported by several authors ${ }^{38-44}$, the charge transfer resistance is related to the process of electron transfer from one phase (electrode) to another (liquid).

The same equivalent circuit model (Tables 5-8) was proposed for the electrochemical behavior simulation for the T0 sample (up to 48 and 72 hours) and for the T1 sample (up to 96 hours). The T2 sample (up to 24 and 72 hours), and T3 sample (up to 24 and 96 hours) showed three time constants. The first two, also observed by other authors $\mathrm{s}^{45,46}$ are: one at a high frequency range, associated with the barrier resistance of the hybrid coating, and another which represents medium frequency range elements which were attributed to an oxide present on the metal/coating interface. Finally, a time constant was also observed at a low frequency range, associated to the charge transfer of the metal ${ }^{47}$.

As for the $\mathrm{T} 3$ film, $\mathrm{CPE}_{\mathrm{HF}} / / \mathrm{R}_{\mathrm{HF}}$ and $\mathrm{CPE}_{\mathrm{MF}} / / \mathrm{R}_{\mathrm{MF}}$ are the cascade sub-circuits making up the response. The high frequency range is associated with the diffusion resistance of the hybrid siloxane-PMMA film, as the micropores represent the conductive pathways that can be widened with the exposure to the electrolyte, promoting easier access of aggressive species to the substrate surface and explaining the diffusion resistance ${ }^{48}$. 

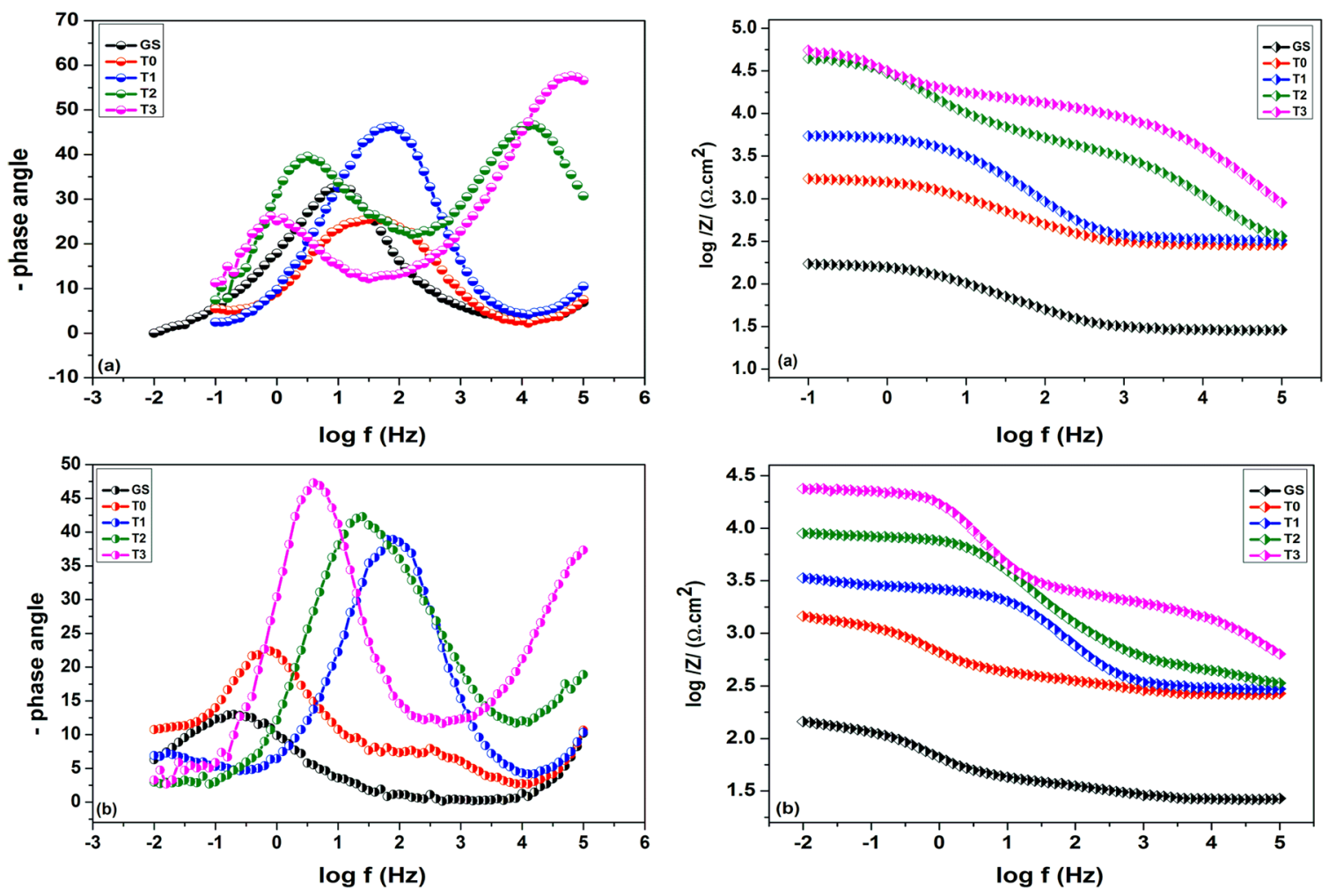

Figure 9. Bode diagrams obtained for the coated samples and for uncoated galvanized steel 0.05 mol.L-1 NaCl: (a) 24 hours and (b) 96 hours.

Table 5. Electrical elements fitted values for the T0 sample up to 96 hours of immersion in a 0.05 mol. $\mathrm{L}^{-1} \mathrm{NaCl}$ solution. The error percentage associated with each parameter value is given in parenthesis.

\begin{tabular}{|c|c|c|c|c|c|}
\hline T0 & $1 \mathrm{~h}$ & $24 \mathrm{~h}$ & $48 h$ & $72 \mathrm{~h}$ & $96 \mathrm{~h}$ \\
\hline Fitted circuit & 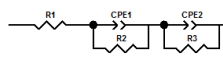 & 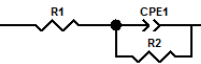 & 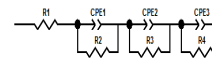 & 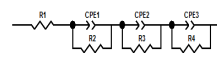 & 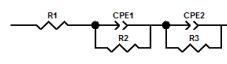 \\
\hline $\mathrm{R}_{\mathrm{S}}\left(\Omega . \mathrm{cm}^{2}\right)$ & $190.7(0.4)$ & $169.7(0.7)$ & $167.3(0.5)$ & $149.8(1.4)$ & $153.3(1.5)$ \\
\hline $\mathrm{CPE}_{\mathrm{HF}}\left(\mathrm{F} \cdot \mathrm{cm}^{-2}\right)$ & $2.97 \times 10^{-5}(1.5)$ & $9.46 \times 10^{-5}(1.9)$ & $1.10 \times 10^{-4}(8.4)$ & $7.16 \times 10^{-5}(31.8)$ & $2.755(14.6)$ \\
\hline $\mathrm{n}_{\mathrm{HF}}$ & $0.75(0.4)$ & $0.62(0.6)$ & $0.64(1.9)$ & $0.81(7.5)$ & $0.51(5.0)$ \\
\hline $\mathrm{R}_{\mathrm{HF}}\left(\Omega . \mathrm{cm}^{2}\right)$ & $1248(0.4)$ & $950.9(0.6)$ & $113.5(2.7)$ & $31.76(18.6)$ & $95.05(6.1)$ \\
\hline $\mathrm{CPE}_{\mathrm{OX}}\left(\mathrm{F} \cdot \mathrm{cm}^{-2}\right)$ & $0.029(10.1)$ & - & $4.28 \times 10^{-4}(0.7)$ & $0.001456(2.4)$ & $1.80 \times 10^{-3}(1.0)$ \\
\hline $\mathrm{n}_{\mathrm{OX}}$ & $0.93(4.6)$ & - & $0.82(0.7)$ & $0.87(1.5)$ & $0.56(0.9)$ \\
\hline $\mathrm{R}_{\mathrm{OX}}\left(\Omega . \mathrm{cm}^{2}\right)$ & $543.4(11.6)$ & - & $645.5(1.5)$ & $315.5(3.6)$ & $1042(1.2)$ \\
\hline $\mathrm{CPE}_{\mathrm{CT}}\left(\mathrm{F} \cdot \mathrm{cm}^{-2}\right)$ & - & - & $0.02082(9.6)$ & $0.004302(6.4)$ & - \\
\hline $\mathrm{n}_{\mathrm{CT}}$ & - & - & $0.82(3.9)$ & $0.24(3.5)$ & - \\
\hline $\mathrm{R}_{\mathrm{CT}}\left(\Omega . \mathrm{cm}^{2}\right)$ & - & - & $55.17(7.2)$ & $14500(1.1)$ & - \\
\hline
\end{tabular}

However, for the T0 and T3 samples (at 1 hour of immersion), for the T1 sample (up to 48 and 72 hours) and for T2 sample (up to 1 hour and 96 hours) with the same equivalent circuit model (Tables 5-8), two time constants were identified. One at a high frequency range, associated with the barrier resistance of the hybrid coating, and the other which represents medium frequency range elements which were attributed to an oxide present on the metal/coating interface. This behavior was observed by other authors ${ }^{47}$.
The T0 sample presented the worst performance among the studied films. This could be explained by the T0 film structure where the radical of the MMA covalently bonded to the TMSM moieties through polymerization reactions can only interact by weak Van der Waals forces. Taking into account these structural considerations, a lower thickness of the film is expected due to the weak bonds and, consequently, not resistant to longs periods of immersion in a $\mathrm{NaCl} 0.05$ mol. $\mathrm{L}^{-1}$ solution. In this film, it was also observed a time constant in 
Table 6. Electrical elements fitted values for the $\mathrm{T} 1$ sample up to 96 hours of immersion in a $0.05 \mathrm{~mol} . \mathrm{L}^{-1} \mathrm{NaCl}$ solution. The error percentage associated with each parameter value is given in parenthesis.

\begin{tabular}{|c|c|c|c|c|c|}
\hline T1 & $1 \mathrm{~h}$ & $24 \mathrm{~h}$ & $48 \mathrm{~h}$ & $72 \mathrm{~h}$ & $96 \mathrm{~h}$ \\
\hline Fitted circuit & 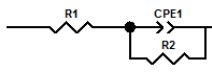 & 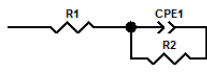 & 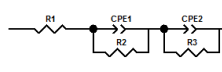 & 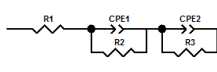 & 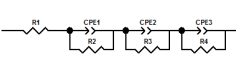 \\
\hline $\mathrm{R}_{\mathrm{S}}\left(\Omega \cdot \mathrm{cm}^{2}\right)$ & $223.9(0.6)$ & $197.3(0.9)$ & $195.4(0.4)$ & $186(0.4)$ & $174.1(0.5)$ \\
\hline $\mathrm{CPE}_{\mathrm{HF}}\left(\mathrm{F} \cdot \mathrm{cm}^{-2}\right)$ & $1.21 \times 10^{-5}(1.1)$ & $1.43 \times 10^{-5}(2.2)$ & $1.81 \times 10^{-5}(1.8)$ & $1.63 \times 10^{-5}(1.5)$ & $1.71 \times 10^{-5}(6.1)$ \\
\hline $\mathrm{n}_{\mathrm{HF}}$ & $0.7(0.3)$ & $0.77(0.5)$ & $0.75(0.5)$ & $0.79(0.4)$ & $0.88(3.5)$ \\
\hline $\mathrm{R}_{\mathrm{HF}}\left(\Omega \cdot \mathrm{cm}^{2}\right)$ & $9756(0.4)$ & $3283(0.6)$ & $1523(1.2)$ & $1424(1.1)$ & 354.5 (19.8) \\
\hline $\mathrm{CPE}_{\mathrm{OX}}\left(\mathrm{F} \cdot \mathrm{cm}^{-2}\right)$ & - & & $3.84 \times 10^{-3}(9.0)$ & $4.56 \times 10^{-3}(8.3)$ & $8.12 \times 10^{-5}(8.3)$ \\
\hline $\mathrm{n}_{\mathrm{OX}}$ & - & & $0.56(7.7)$ & $0.47(8.3)$ & $0.69(3.7)$ \\
\hline $\mathrm{R}_{\mathrm{OX}}\left(\Omega \cdot \mathrm{cm}^{2}\right)$ & - & & $871.2(10.4)$ & $1506(19.2)$ & $1047(10.7)$ \\
\hline $\mathrm{CPE}_{\mathrm{CT}}\left(\mathrm{F} \cdot \mathrm{cm}^{-2}\right)$ & - & & & & $0.005534(19.2)$ \\
\hline $\mathrm{n}_{\mathrm{CT}}$ & - & & & & $0.45(18.6)$ \\
\hline $\mathrm{R}_{\mathrm{CT}}\left(\Omega \cdot \mathrm{cm}^{2}\right)$ & - & & & & 7293 (16.9) \\
\hline
\end{tabular}

Table 7. Electrical elements fitted values for the $\mathrm{T} 2$ sample up to 96 hours of immersion in a $0.05 \mathrm{~mol} . \mathrm{L}^{-1} \mathrm{NaCl}$ solution. The error percentage associated with each parameter value is given in parenthesis.

\begin{tabular}{|c|c|c|c|c|c|}
\hline $\mathbf{T 2}$ & $1 \mathrm{~h}$ & $24 \mathrm{~h}$ & $48 \mathrm{~h}$ & $72 \mathrm{~h}$ & $96 \mathrm{~h}$ \\
\hline Fitted circuit & 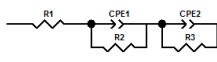 & 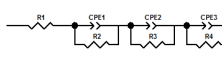 & 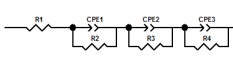 & 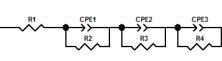 & 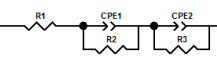 \\
\hline $\mathrm{R}_{\mathrm{S}}\left(\Omega \cdot \mathrm{cm}^{2}\right)$ & $108(4.3)$ & $122.8(5.4)$ & $106.4(3.7)$ & $228.2(1.5)$ & $224.5(0.7)$ \\
\hline $\mathrm{CPE}_{\mathrm{HF}}\left(\mathrm{F} \cdot \mathrm{cm}^{-2}\right)$ & $1.49 \times 10^{-4}(7.5)$ & $2.6 \times 10^{-7}(15.3)$ & $1.5 \times 10^{-6}(26.4)$ & $1.2 \times 10^{-4}(10.9)$ & $3.45 \times 10^{-5}(8.8)$ \\
\hline $\mathrm{n}_{\mathrm{HF}}$ & $0.82(1.1)$ & $0.82(2.6)$ & $0.67(4.2)$ & $0.45(3.2)$ & $0.65(1.4)$ \\
\hline $\mathrm{R}_{\mathrm{HF}}\left(\Omega . \mathrm{cm}^{2}\right)$ & $8254(3.5)$ & $1430(9.1)$ & $340(10.7)$ & $1034(48.0)$ & 890.7 (27.7) \\
\hline $\mathrm{CPE}_{\mathrm{OX}}\left(\mathrm{F} \cdot \mathrm{cm}^{-2}\right)$ & $9.23 \times 10^{-6}(3.2)$ & $9.24 \times 10^{-6}(1.4)$ & $6.26 \times 10^{-5}(7.5)$ & $1.51 \times 10^{-5}(2.7)$ & $2.00 \times 10^{-5}(7.4)$ \\
\hline $\mathrm{n}_{\mathrm{ox}}$ & $0.58(2.4)$ & $0.86(1.1)$ & $0.43(3.9)$ & $0.82(2.3)$ & $0.78(1.7)$ \\
\hline $\mathrm{R}_{\mathrm{OX}}\left(\Omega . \mathrm{cm}^{2}\right)$ & $48502(2.4)$ & $23381(1.7)$ & $3322(14.4)$ & $4084(9.8)$ & 3297 (7.6) \\
\hline $\mathrm{CPE}_{\mathrm{CT}}\left(\mathrm{F} \cdot \mathrm{cm}^{-2}\right)$ & - & $1.4 \times 10^{-5}(10.2)$ & $1.09 \times 10^{-5}(1.3)$ & $1.8 \times 10^{-2}(58.9)$ & - \\
\hline $\mathrm{n}_{\mathrm{CT}}$ & - & $0.53(4.0)$ & $0.91(1.3)$ & $0.94(16.5)$ & - \\
\hline $\mathrm{R}_{\mathrm{CT}}\left(\Omega \cdot \mathrm{cm}^{2}\right)$ & - & $3798(8.5)$ & $10956(3.8)$ & $496.1(32.0)$ & - \\
\hline
\end{tabular}

Table 8. Electrical elements fitted values for the T3 sample up to 96 hours of immersion in a $0.05 \mathrm{~mol} . \mathrm{L}^{-1} \mathrm{NaCl}$ solution. The error percentage associated with each parameter value is given in parenthesis.

\begin{tabular}{|c|c|c|c|c|c|}
\hline T3 & $1 \mathrm{~h}$ & $24 \mathrm{~h}$ & $48 h$ & $72 \mathrm{~h}$ & $96 \mathrm{~h}$ \\
\hline \multicolumn{6}{|l|}{ Fitted circuit } \\
\hline $\mathrm{R}_{\mathrm{S}}\left(\Omega \cdot \mathrm{cm}^{2}\right)$ & - & - & - & - & \\
\hline $\mathrm{CPE}_{\mathrm{HF}}\left(\mathrm{F} \mathrm{cm}^{-2}\right)$ & $7.45 \times 10^{-8}(8.1)$ & $6.47 \times 10^{-8}(12.6)$ & $3.4 \times 10^{-7}(20.7)$ & $2.2 \times 10^{-7}(36.3)$ & $1.9 \times 10^{-7}(42.7)$ \\
\hline $\mathrm{n}_{\mathrm{HF}}$ & $0.74(0.8)$ & $0.81(1.9)$ & $0.67(3.8)$ & $0.74(5.4)$ & $0.74(6.2)$ \\
\hline $\mathrm{R}_{\mathrm{HF}}\left(\Omega \cdot \mathrm{cm}^{2}\right)$ & $2107(1.5)$ & $3618(6.8)$ & $1515(12.5)$ & $563.2(15.3)$ & $348.7(12.8)$ \\
\hline $\mathrm{CPE}_{\mathrm{OX}}\left(\mathrm{F} \cdot \mathrm{cm}^{-2}\right)$ & $4.93 \times 10^{-7}(1.8)$ & $3.0 \times 10^{-6}(10.5)$ & $2.92 \times 10^{-5}(28.8)$ & $3.4 \times 10^{-5}(24.5)$ & $1.21 \times 10^{-5}(1.2)$ \\
\hline $\mathrm{n}_{\mathrm{OX}}$ & $0.75(0.4)$ & $0.53(1.2)$ & $0.42(4.5)$ & $0.36(3.1)$ & $0.96(0.6)$ \\
\hline $\mathrm{R}_{\mathrm{OX}}\left(\Omega \cdot \mathrm{cm}^{2}\right)$ & $80064(0.8)$ & $7205(3.1)$ & $1542(11.7)$ & $1314(5.2)$ & $9098(1.3)$ \\
\hline $\mathrm{CPE}_{\mathrm{CT}}\left(\mathrm{F} \cdot \mathrm{cm}^{-2}\right)$ & - & $1.57 \times 10^{-5}(1.5)$ & $1.24 \times 10^{-5}(0.9)$ & $1.19 \times 10^{-5}(0.9)$ & $2.43 \times 10^{-4}(6.1)$ \\
\hline $\mathrm{n}_{\mathrm{CT}}$ & - & $0.81(1.2)$ & $0.9(0.6)$ & $0.92(0.4)$ & $0.24(6.5)$ \\
\hline $\mathrm{R}_{\mathrm{CT}}\left(\Omega \cdot \mathrm{cm}^{2}\right)$ & - & $26395(1.7)$ & $15649(0.7)$ & $12555(0.6)$ & $2958(11.7)$ \\
\hline
\end{tabular}


the medium to low frequency range, indicating an acceleration of the interfacial process associated with the zinc oxides on the substrate surface.

Figure 10 show the evolution of the coating properties (that is, the resistance and capacitance, respectively) as a function of the immersion time. Generally, the high frequency resistance values (Figure 9) decreased during the first hours of immersion, due to the development of conductive pathways inside the coating ${ }^{49}$. The T1 and T2 samples exhibited the highest resistance the first hours of immersion (Figure 9), while the T3 sample showed higher resistance values at 24 and 48 hours of immersion. This is due to the larger layer thicknesses obtained for the T3 system (Figure 4 and Table 1) compared to the other samples. Moreover, this demonstrates the excellent synergistic effect of the TEOS/ TMSM covalent bonds.

The evolution of the coating resistance is a major characteristic of the barrier properties of a protective layer ${ }^{50}$. Both systems showed a sharp reduction of the resistance values from 1 hour to 48 hours of immersion, the T2 and T1 samples, more sharply. Subsequently, the resistance of the coating for the T3 sample decreases slowly over an immersion time of 72 hours, which reflects the stability of the coating and its good barrier properties ${ }^{51}$. In contrast, the coating without TEOS (T0) loses its barrier properties after all times of immersion. This rapid decrease is related to the formation of new defects and pores in the coatings $\mathrm{s}^{51}$. This could be explained by the T0 sample film structure, where the MMA radical, covalently bonded to the TMSM moieties through polymerization reactions, can only interact by weak Van der Waals forces. Taking into account these structural considerations, a lower film thickness is expected, due to the weak bonding (Figure 2 and Table 1). Consequently, there is less resistance in long periods of immersion in 0.05 mol. $\mathrm{L}^{-1} \mathrm{NaCl}$.

However, it is observed that the variation between the $\mathrm{T} 1, \mathrm{~T} 2$ and $\mathrm{T} 3$ samples is negligible due to the fact all these systems present TEOS in their composition. When there is a perfect synergistic effect in the formulation, there is a greater formation of covalent bonds, and consequently, a greater cross-linking and a greater hydrophobicity (contact angle), as well as higher resistance values due to a better barrier effect. Besides, a higher densification of this film was observed ${ }^{23}$ due to the covalent bonds of the organic and inorganic precursors. This demonstrates the synergistic effect of the TMSM and TEOS precursors presence in the films.

Figure 11 shows a physical model for the studied samples. In this model, two time constants are presented, one at a high frequency range, possibly associated to the diffusion resistance of the hybrid film, and the other at a medium frequency range, related to corrosion products (zinc oxides) on the substrate surface.

For the uncoated galvanized steel (Table 9), two time constants were observed over the entire immersion time (1, 24, 48, 72 and 96 hours). The phenomenon at low frequency may be related to the charge transfer resistance of the metal. The response of the charge transfer becomes shifted to lower frequencies as the active area expands, increasing the capacitance.

These results indicate the degradation of the zinc oxides and the probable metal corrosion. Not only that, but new process governed by diffusion apparently begins as indicated

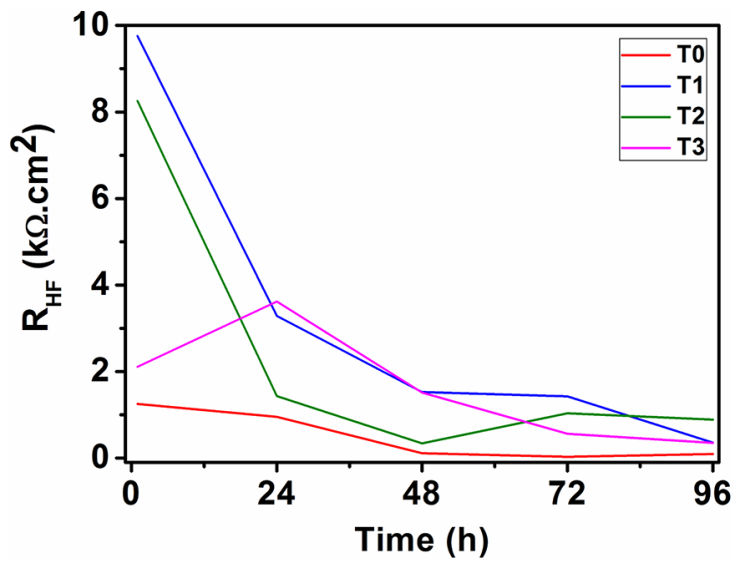

Figure 10. Evolution of the resistance of hybrid coatings for the samples, in relation to the immersion time, in a $0.05 \mathrm{~mol} . \mathrm{L}^{-1} \mathrm{NaCl}$ solution.

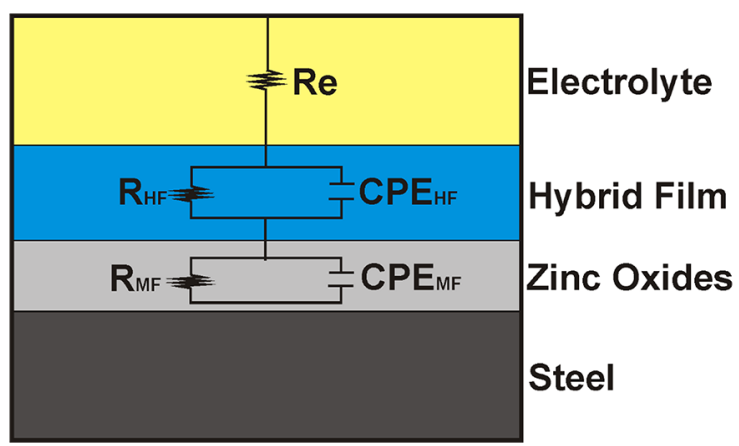

Figure 11. Physical model of the studied samples, presenting the general hybrid film, zinc oxide and steel.

by the low value of $\mathrm{n}$. This explanation was corroborated by the fact that the initially high resistance declines drastically and that red corrosion products were observed on the electrode surface once the experiment was finished, indicating the formation of iron oxides 5 .

Meanwhile, another process with very low resistance appears at the medium frequency range, associated with the zinc oxide on the substrate surface, which may result from the cathodic reaction or from the precipitation of the zinc hydroxide as shown the Equation $1^{52}$.

$\mathrm{Zn}^{2+}+2 \mathrm{OH}^{-} \rightarrow \mathrm{Zn}(\mathrm{OH})_{2}$

According to the Pourbaix diagram for zinc, the zinc hydroxide is stable at $\mathrm{pH}$ values above 8 , a value that is easily reached over steel. Furthermore, carbonates can also be formed, eventually leading to hydrozincite, as shown the Equation $2^{53}$.

$\mathrm{Zn}(\mathrm{OH})_{2}+4 \mathrm{Zn}^{2+}+4 \mathrm{OH}^{-}+2 \mathrm{CO}_{3}^{2-} \rightarrow \mathrm{Zn}_{5}\left(\mathrm{CO}_{3}\right)_{2}(\mathrm{OH})_{6}$

The majority of the publications applying impedance to corrode systems use continuous metals and not galvanic couples. In such systems, the interpretation of the impedance spectra may be facilitated by the results for the separate metals. In this study, it is interesting to note that the GS showed lower values of resistance and higher values of capacitance 
Table 9. Electrical elements fitted values for GS up to 96 hours of immersion in a 0.05 mol.L $\mathrm{L}^{-1} \mathrm{NaCl}$ solution.

\begin{tabular}{|c|c|c|c|c|c|}
\hline GS & $1 \mathrm{~h}$ & $24 \mathrm{~h}$ & $48 \mathrm{~h}$ & $72 \mathrm{~h}$ & $96 \mathrm{~h}$ \\
\hline & $\overbrace{}^{\text {Rs }} \longrightarrow \overbrace{\text { CPFox }}^{\longrightarrow}$ & $\stackrel{\text { CPEox }}{\longrightarrow}$ & $\stackrel{\text { CPEox }}{\longrightarrow}$ & $\stackrel{\text { CPEox }}{\longrightarrow}$ & $\overbrace{}^{\text {Rs }} \stackrel{\text { CPEox }}{\longrightarrow}$ \\
\hline Fitted circuit & 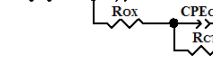 & 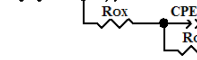 & $\overbrace{(\mathrm{R}}^{\mathrm{Rox}}$ & $\overbrace{}^{\text {Rox }} \overbrace{}^{C}$ & 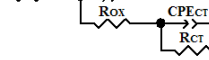 \\
\hline $\mathrm{R}_{\mathrm{S}}\left(\Omega . \mathrm{cm}^{2}\right)$ & $151.0(0.9)$ & $150.8(1.4)$ & $148.5(1.1)$ & $151.3(1.3)$ & $146.9(1.2)$ \\
\hline $\mathrm{CPE}_{\mathrm{OX}}\left(\mathrm{Fcm}^{-2}\right)$ & $1.0 \times 10^{-6}(10.8)$ & $1.08 \times 10^{-4}(3.2)$ & $2.80 \times 10^{-4}(9.8)$ & $2.41 \times 10^{-4}(2.0)$ & $2.29 \times 10^{-4}(8.9)$ \\
\hline $\mathrm{n}_{\mathrm{OX}}$ & $0.75(2.6)$ & $0.74(8.1)$ & $0.66(8.1)$ & $0.90(9.5)$ & $0.80(9.1)$ \\
\hline $\mathrm{R}_{\mathrm{OX}}\left(\Omega \cdot \mathrm{cm}^{2}\right)$ & $466(3.2)$ & $468(3.1)$ & $252(7.3)$ & $192(8.7)$ & $178(9.9)$ \\
\hline $\mathrm{CPE}_{\mathrm{CT}}\left(\mathrm{Fcm}^{-2}\right)$ & $6.53 \times 10^{-3}(2.2)$ & $6.5 \times 10^{-3}(2.7)$ & $14.6 \times 10^{-3}(6.8)$ & $1.6 \times 10^{-3}(6.1)$ & $3.67 \times 10^{-3}(3.1)$ \\
\hline $\mathrm{n}_{\mathrm{CT}}$ & $0.82(5.1)$ & $0.81(6.3)$ & $0.90(7.6)$ & $0.30(9.3)$ & $0.55(3.6)$ \\
\hline $\mathrm{R}_{\mathrm{CT}}\left(\Omega \cdot \mathrm{cm}^{2}\right)$ & $1085(7.2)$ & $1155(0.9)$ & $956(5.6)$ & $1231(2.1)$ & $867(2.8)$ \\
\hline
\end{tabular}
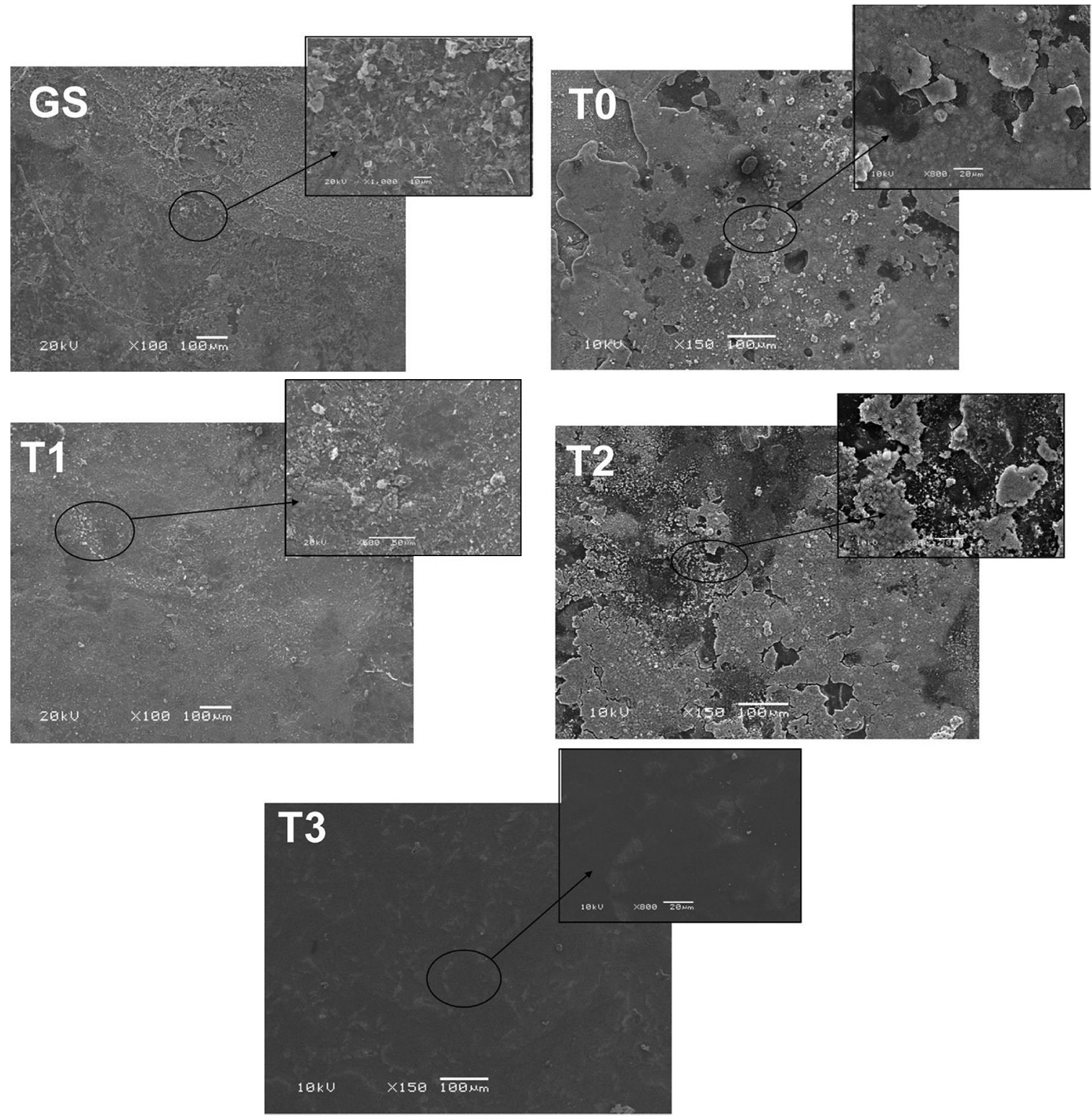

Figure 12. Images obtained after the electrochemical impedance tests. 
(Table 9) compared to the hybrid coatings (Tables 5-8), and lower impedance modulus and phase angle (Figure 9) in relation to the hybrid coatings at 96 hours of immersion.

As per Figure 12, the only coating that did not show cracks after the electrochemical impedance test was the T3 system, indicating that this coating has a good performance.

\subsection{Mechanical characterization}

The tribology test is a very important technique for determining the wear resistance of the film ${ }^{54-57}$. In this test, the proportionality between the frictional force and load applied results in a friction coefficient, considering that the force is also proportional to the actual contact area.

Hanetho et al. ${ }^{57}$ evaluated the wear resistance silane-based coatings applied to steel. In this study, the authors reported that the abrasion resistance (wear) of the films improved with the decrease of the water $\mathrm{pH}$ used during the silane hydrolysis.

Figure 13 shows the coefficient of friction (COF) with sliding time for the samples. The system without the addition of the TEOS presented a worse performance in the wear test than the T0 sample, which presents a higher concentration of PMMA. Taking into account these structural

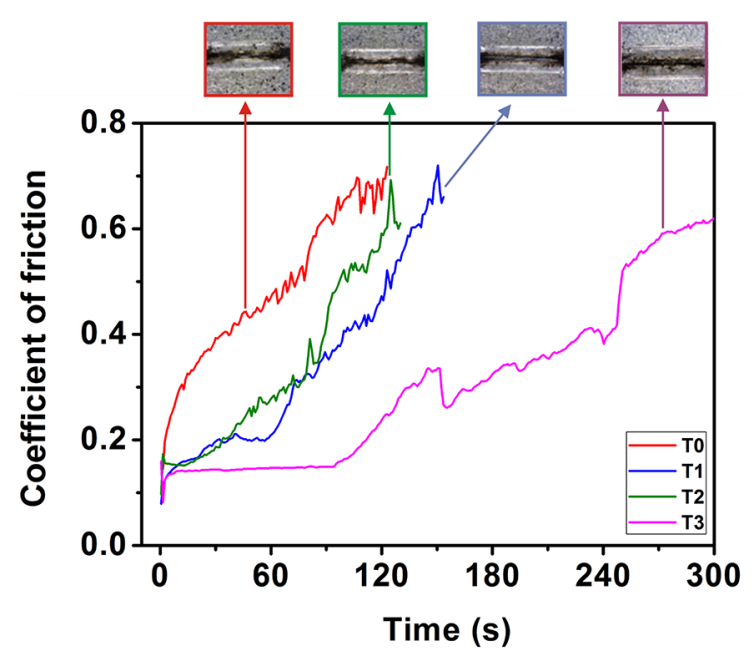

Figure 13. Coefficient of friction of the hybrid coatings studied.

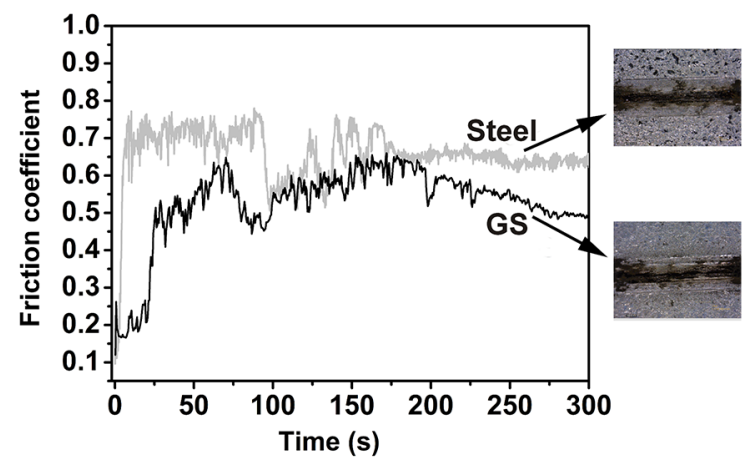

Figure 14. Coefficient of friction of the galvanized steel without coating, and of steel. considerations, a lower coating thickness is expected; and due to the weak bonds the film does not resist to longer periods of time in the wear test.

The higher the TEOS addition of the hybrid coating, for T3 sample, for example, the better is the hydrolysis condition, and, subsequently, the crosslinking of this sample, and the higher its wear resistance will be, as observed in Figure 11. However, although the T1 and T2 samples have shown the best performance in the wear test, the endurance time was low due to the system not having obtained the synergistic effect of the TMSM and TEOS precursors present in the hybrid coating.

The variation in the friction coefficient shown in Figure 14 determines the change of the tribological pair, that is, the rupture of the coating in the iron $(\mathrm{Fe})$ and in the galvanized steel (GS). As seen in the Figure 13, the coefficients of friction of the samples with hybrid coatings reached a stable level close to the one of $\mathrm{Fe}(\mu=0.7)$ after the breaking of the coatings. This indicates that the coatings had a high adherence on $\mathrm{Zn}$ such that upon breaking the hybrid coating also breaks the $\mathrm{Zn}$ coating.

\section{Conclusions}

The hybrid siloxane-PMMA coatings which were studied showed a regular coverage over zinc coating. However, in some systems, cracks and discontinuities were observed, which compromised the barrier effect. Moreover, a shift in the open circuit potential toward less active potentials after silane coating deposition was also observed.

The T0 system showed the second highest thickness layer value, but it showed cracks and discontinuities. The T2 and T1 samples showed the lowest thickness values in relation to the others, however, the T2 sample showed a better electrochemical performance than the T1 sample since it did not present cracks and discontinuities. The T3 system has proven to be the best, due to its highest thickness layer value and to the absence of cracks or discontinuities. The electrochemical tests showed that the T3 system presented the best performance when compared to other tested systems.

Based on the results, one can conclude that the T3 system presented the best performance. This result is due to the formation of a compact net after hydrolysis and cross-linking of TEOS. Thus, the addition of a higher ratio of TEOS:TMSM contributed to the film formation. This ratio was sufficient to produce the synergistic effect of the presence of TMSM and TEOS precursors in the hybrid film.

Therefore, these hybrid films present a promissing alternative as a substitute for the chemical conversion coatings based in $\mathrm{Cr}(\mathrm{IV})$ ions.

\section{Acknowledgements}

The authors would like to express their gratitude to CNPQ, Finep, FAPITEC/PRONEX and CAPES for the financial support. 


\section{References}

1. Kong G, Lu J, Zhang S, Che C and Wu H. A comparative study of molybdate/silane composite films on galvanized steel with different treatment process. Surface and Coatings Technology. 2010; 205(2):545-550. http://dx.doi.org/10.1016/j. surfcoat.2010.07.033.

2. Kong $\mathrm{G}, \mathrm{Lu} \mathrm{J}$ and $\mathrm{Wu} \mathrm{H}$. Post treatment of silane and cerium salt as chromate replacers on galvanized steel. Journal of Rare Earths. 2009; 27(1):164-168. http://dx.doi.org/10.1016/S10020721(08)60213-6.

3. Mittal KL. Silanes and other coupling agents. Boca Raton: CRC Press; 1992. v. 1.

4. Deflorian F, Rossi S and Fedrizzi L. Silane pre-treatments on copper and aluminium. Electrochimica Acta. 2006; 51(27):60976103. http://dx.doi.org/10.1016/j.electacta.2006.02.042.

5. Ferreira MGS, Duarte RG, Montemor MF and Simões AMP. Silanes and rare earth salts as chromate replacers for pre-treatments on galvanised steel. Electrochimica Acta. 2004; 49(17-18):29272935. http://dx.doi.org/10.1016/j.electacta.2004.01.051.

6. Ranney MW, Berger SE and Marsden JG. Interfaces in polymer matrix composites. In: Plueddemann EP. Composite materials. New York: Academic Press; 1974. v. 6, chap. 5.

7. Zomorodian A, Brusciotti F, Fernandes A, Carmezim MJ, Silva TM, Fernandes JCS, et al. Anti-corrosion performance of a new silane coating for corrosion protection of AZ31 magnesium alloy in Hank's solution. Surface and Coatings Technology. 2012; 206(21):4368-4375. http://dx.doi.org/10.1016/j. surfcoat.2012.04.061.

8. Zhu D and van Ooij WJV. Corrosion protection of AA 2024-T3 by bis-[3-(triethoxysilyl)propyl]tetrasulfide in sodium chloride solution.: Part 2: mechanism for corrosion protection. Corrosion Science. 2003; 45(10):2177-2197. http://dx.doi.org/10.1016/ S0010-938X(03)00061-1.

9. Zhu D and van Ooij WJV. Corrosion protection of metals by water-based silane mixtures of bis-[trimethoxysilylpropyl]amine and vinyltriacetoxysilane. Progress in Organic Coatings. 2004; 49(1):42-53. http://dx.doi.org/10.1016/j.porgcoat.2003.08.009.

10. Kunst SR, Cardoso HRP, Oliveira CT, Santana JA, Sarmento VHV, Muller IL, et al. Corrosion resistance of siloxane-poly(methyl methacrylate) hybrid films modified with acetic acid on tin plate substrates: influence of tetraethoxysilane addition. Applied Surface Science. 2014; 298:1-11. http://dx.doi.org/10.1016/j. apsusc.2013.09.182.

11. Suegama PH, Melo HG, Recco AAC, Tschiptschin AP and Aoki IV. Corrosion behavior of carbon steel protected with single and bi-layer of silane films filled with silica nanoparticles. Surface and Coatings Technology. 2008; 202(13):2850-2858. http://dx.doi.org/10.1016/j.surfcoat.2007.10.028.

12. Sakai RT, Cruz FMDL, Melo HG, Benedetti AV, Santilli CV and Suegama PH. Electrochemical study of TEOS, TEOS/MPTS, MPTS/MMA and TEOS/MPTS/MMA films on tin coated steel in $3.5 \% \mathrm{NaCl}$ solution. Progress in Organic Coatings. 2012; 74(2):288-301. http://dx.doi.org/10.1016/j.porgcoat.2012.01.001.

13. Omar S, Repp F, Desimone PM, Weinkamer R, Wagermaier W, Ceré S, et al. Sol-gel hybrid coatings with strontium-doped 45S5 glass particles for enhancing the performance of stainless steel implants: electrochemical, bioactive and in vivo response. Journal of Non-Crystalline Solids. 2015; 425:1-10. http://dx.doi. org/10.1016/j.jnoncrysol.2015.05.024.
14. Dalmoro V, Santos JHZ, Armelin E, Alemán C and Azambuja DS Sol-gel hybrid films based on organosilane and montmorillonite for corrosion inhibition of AA2024. Journal of Colloid and Interface Science. 2014; 426:308-313. http://dx.doi.org/10.1016/j. jcis.2014.04.021. PMid:24863798.

15. Kunst SR, Ludwig GA, Cardoso HRP, Santana JA, Sarmento VHV and Malfatti CF. Hybrid films with (Trimethoxysilylpropyl) methacrylate (TMSM), poly (Methyl methacrylate) PMMA and tetraethoxysilane (TEOS) applied on tinplate. Materials Research. 2014; 17:75-81. http://dx.doi.org/10.1590/S151614392014005000069 .

16. Kunst SR, Cardoso HRP, Beltrami LVR, Oliveira CT, Menezes TL, Ferreira JZ, et al. New sol-gel formulations to increase the barrier effect of a protective coating against the corrosion and wear of galvanized steel. Materials Research. 2015; 18(1):138150. http://dx.doi.org/10.1590/1516-1439.288914.

17. Kunst SR, Beltrami LVR, Cardoso HRP, Santana JA, Sarmento VHV, Müller IL, et al. Characterization of siloxane-poly(methyl methacrylate) hybrid films obtained on a tinplate substrate modified by the addition of organic and Inorganic Acids. Materials Research. 2015; 18(1):151-163. http://dx.doi. org/10.1590/1516-1439.299514.

18. Palanivel V. Modified silane thin films as an alternative to chromates for corrosion protection of AA2024-T3 alloy. [Dissertation]. Ohio: University of Cincinnati; 2003.

19. Delattre L, Dupuy C and Babonneau F. Characterization on the hydrolysis and polymerization processes of methacryloxypropyltrimethoxylane. Journal of Sol-Gel Science and Technology. 1994; 2(1-3):185-188. http://dx.doi.org/10.1007/ BF00486238.

20. Ooij WJV, Zhu D, Stacy M, Seth A, Mugada T, Gandhi J. Corrosion protection properties of organofunctional silanes: an overview. Tsinghua Science and Technology. 2005; 10(6):639664. http://dx.doi.org/10.1016/S1007-0214(05)70134-6.

21. Flis J and Kanoza M. Electrochemical and surface analytical study of vinyl-triethoxy silane films on iron after exposure to air. Electrochimica Acta. 2006; 51(11):2338-2345. http://dx.doi. org/10.1016/j.electacta.2005.01.065.

22. Kozhukharov S, Kozhukharov V, Schem M, Aslan M, Wittmar M, Wittmar A, et al. Protective ability of hybrid nano-composite coatings with cerium sulphate as inhibitor against corrosion of AA2024 aluminium alloy. Progress in Organic Coatings. 2012; 73(1):95-103. http://dx.doi.org/10.1016/j.porgcoat.2011.09.005.

23. Wang M, He D, Xie H, Fu L, Yu Y and Zhang Q. Characterization of bis-[triethoxysilylpropyl] tetrasulfide layers on aluminum based on water-based silanization solution. Thin Solid Films. 2012; 520(17):5610-5615. http://dx.doi.org/10.1016/j.tsf.2012.04.028

24. Zaioncz S. Relationships between nanostructure and dynamicmechanical properties of epoxy network containing PMMAmodified silsesquioxane. Express Polymer Letters. 2009; 3(6):340-351. http://dx.doi.org/10.3144/expresspolymlett.2009.43.

25. Magonov SN, Elings V and Whangbo MH. Phase imaging and stiffness in tapping-mode atomic force microscopy. Surface Science. 1997; 375(2-3):385-391. http://dx.doi.org/10.1016/ S0039-6028(96)01591-9.

26. Vanin FM, Sobral PJA, Menegalli FC, Carvalho RA and Habitante AMBQ. Effects of plasticizers and their concentrations on thermal and functional properties of gelatin-based films. Food Hydrocolloids. 2005; 19(5):899-907. http://dx.doi.org/10.1016/j. foodhyd.2004.12.003. 
27. Hansal WEG, Hansal S, Pölzler M, Kornherr A, Zifferer G and Nauer GE. Investigation of polysiloxane coatings as corrosion inhibitors of zinc surfaces. Surface and Coatings Technology. 2006; 200(9):3056-3063. http://dx.doi.org/10.1016/j. surfcoat.2005.01.049.

28. Campestrini P, van Westing EP and de Wit JH. Influence of surface preparation on performance of chromate conversion coatings on Alclad 2024 aluminium alloy: Part II: EIS investigation. Electrochimica Acta. 2001; 46(17):2631-2647. http://dx.doi. org/10.1016/S0013-4686(01)00476-5.

29. Palomino LEM, Suegama PH, Aoki IV, Pászti Z and de Melo HG. Investigation of the corrosion behaviour of a bilayer cerium-silane pre-treatment on $\mathrm{Al} 2024-\mathrm{T} 3$ in $0.1 \mathrm{M} \mathrm{NaCl}$. Electrochimica Acta. 2007; 52(27):7496-7505. http://dx.doi. org/10.1016/j.electacta.2007.03.002.

30. Zhang X, Wu Y, He S and Yang D. Structural characterization of sol-gel composites using TEOS/MEMO as precursors. Surface and Coatings Technology. 2007; 201(12):6051-6058. http://dx.doi.org/10.1016/j.surfcoat.2006.11.012.

31. Suegama PH, Sarmento VHV, Montemor MF, Benedetti AV, Melo HG, Aoki IV, et al. Effect of cerium (IV) ions on the anticorrosion properties of siloxane-poly(methyl methacrylate) based film applied on tin coated steel. Electrochimica Acta. 2010; 55(18):5100-5109. http://dx.doi.org/10.1016/j. electacta.2010.04.002.

32. Zhu D, Ooij WJV and Wim D. Corrosion protection of metals by silane surface treatment. Cincinnati: University of Cincinnati; 2005.

33. Xia F and Xu SA. Effect of surface pre-treatment on the hydrophilicity and adhesive properties of multilayered laminate used for lithium battery packaging. Applied Surface Science. 2013; 268:337-342. http://dx.doi.org/10.1016/j.apsusc.2012.12.091.

34. Behzadnasab M, Mirabedini SM, Kabiri K and Jamali S. Corrosion performance of epoxy coatings containing silane treated $\mathrm{ZrO} 2$ nanoparticles on mild steel in $3.5 \% \mathrm{NaCl}$ solution. Corrosion Science. 2011; 53(1):89-98. http://dx.doi.org/10.1016/j. corsci.2010.09.026.

35. Hammer P, Schiavetto MG, Dos Santos FC, Benedetti AV, Pulcinelli SH and Santilli CV. Improvement of the corrosion resistance of polysiloxane hybrid coatings by cerium doping. Journal of Non-Crystalline Solids. 2010; 356(44-49):2606-2612. http://dx.doi.org/10.1016/j.jnoncrysol.2010.05.013.

36. Clermont RFS. Design of hybrid organic-inorganic materials synthesized via sol-gel chemistry. New Journal of Chemistry. 1994; 18:1007-1047.

37. Hirschorn B, Orazem ME, Tribollet B, Vivier V, Frateur I and Musiani M. Determination of effective capacitance and film thickness from constant-phase-element parameters. Electrochimica Acta. 2010; 55(21):6218-6227. http://dx.doi. org/10.1016/j.electacta.2009.10.065.

38. Fedel M, Druart M-E, Olivier M, Poelman M, Deflorian F and Rossi S. Compatibility between cataphoretic electro-coating and silane surface layer for the corrosion protection of galvanized steel. Progress in Organic Coatings. 2010; 69(2):118-125. http://dx.doi.org/10.1016/j.porgcoat.2010.04.003.

39. Bakhshandeh E, Jannesari A, Ranjbar Z, Sobhani S and Saeb MR. Anti-corrosion hybrid coatings based on epoxy-silicananocomposites: toward relationship between the morphologyand EIS data. Progress in Organic Coatings. 2014; 77(7):1169-1183. http://dx.doi.org/10.1016/j.porgcoat.2014.04.005.
40. Ansari F, Naderi R and Dehghanian C. Study on the protective function of cloisite incorporated silane sol-gel coatings cured at different conditions. Applied Clay Science. 2015; 114:93-102. http://dx.doi.org/10.1016/j.clay.2015.05.009.

41. Li J, Ecco L, Fedel M, Ermini V, Delmas G and Pan J. In-situ AFM and EIS study of a solventborne alkyd coating withnanoclay for corrosion protection of carbon steel. Progress in Organic Coatings. 2015; 87:179-188. http://dx.doi.org/10.1016/j. porgcoat.2015.06.003.

42. Jiang M-Y, Wu L-K, Hu J-M and Zhang J-Q. Silane-incorporated epoxy coatings on aluminum alloy (AA2024). Part 1: improved corrosion performance. Corrosion Science. 2014; 92:118-126. http://dx.doi.org/10.1016/j.corsci.2014.11.046.

43. Souiri M, Blel N, Sboui D, Mhamdi L, Epalle T, Mzoughi R, et al. AFM, CLSM and EIS characterization of the immobilization of antibodies on indium-tin oxide electrode and their capture of Legionella pneumophila. Talanta. 2014; 118:224-230. http:// dx.doi.org/10.1016/j.talanta.2013.09.049. PMid:24274292.

44. Yuan X, Yue ZF, Chen X, Wen SF, Li L and Feng T. EIS study of effective capacitance and water uptake behaviors of silicone-epoxy hybrid coatings on mild steel. Progress in Organic Coatings. 2015; 86:41-48. http://dx.doi.org/10.1016/j. porgcoat.2015.04.004.

45. Garcia-Heras M, Jimenez-Morales A, Casal B, Galvan JC, Radzki S and Villegas MA. Preparation and electrochemical study of cerium-silica sol-gel thin films. Journal of Alloys and Compounds. 2004; 380(1-2):219-224. http://dx.doi.org/10.1016/j. jallcom.2004.03.047.

46. Galio AF, Lamaka SV, Zheludkevich ML, Dick LFP, Müller IL and Ferreira MGS. Inhibitor-doped sol-gel coatings for corrosion protection of magnesium alloy AZ31. Surface and Coatings Technology. 2010; 204(9-10):1479-1486. http://dx.doi. org/10.1016/j.surfcoat.2009.09.067.

47. Zandi Zand R, Verbeken K and Adriaens A. Evaluation of the corrosion inhibition performance of silane coatings filled with cerium salt-activated nanoparticles on hot-dip galvanized steel substrates. International Journal of Electrochemical Science. 2013; 8:4927-4940.

48. Duarte RG, Castela AS and Ferreira MGS. Influence of the solution cation mobility on the water uptake estimation of PVC plastisol freestanding films by EIS. Progress in Organic Coatings. 2006; 57(4):408-415. http://dx.doi.org/10.1016/j. porgcoat.2006.09.026.

49. Montemor MF, Pinto R and Ferreira MGS. Chemical composition and corrosion protection of silane films modified with $\mathrm{CeO}_{2}$ nanoparticles. Electrochimica Acta. 2009; 54(22):5179-5189. http://dx.doi.org/10.1016/j.electacta.2009.01.053.

50. Schem M, Schmidt T, Gerwann J, Wittmar M, Veith M, Thompson $\mathrm{GE}$, et al. $\mathrm{CeO}_{2}$-filled sol-gel coatings for corrosion protection of AA2024-T3 aluminium alloy. Corrosion Science. 2009; 51(10):2304-2315. http://dx.doi.org/10.1016/j.corsci.2009.06.007.

51. Roohangiz Z, Kim V and Annemie A. Influence of the cerium concentration on the corrosion performance of Ce-doped silica hybrid coatings on hot dip galvanized steel substrates. International Journal of Electrochemical Science. 2013; 8:548563.

52. Simões AM and Fernandes JCS. Studying phosphate corrosion inhibition at the cut edge of coil coated galvanized steel using the SVET and EIS. Progress in Organic Coatings. 2010; 69(2):219224. http://dx.doi.org/10.1016/j.porgcoat.2010.04.022. 
53. Ogle K, Morel S and Jacquet D. Observation of self-healing functions on the cut edge of galvanized steel using SVET and $\mathrm{pH}$ microscopy corrosion, passivation, and anodic films. Journal of the Electrochemical Society. 2006; 153(1):B1-B5. http://dx.doi.org/10.1149/1.2126577.

54. Satyanarayana N, Sinha SK and Srinivasan MP. Friction and wear life evaluation of silane based self assembled monolayers on silicon surface. Tribology and Interface Engineering Series. 2005; 48:821-826. http://dx.doi.org/10.1016/S01678922(05)80084-7.

55. Park JO, Rhee KY and Park SJ. Silane treatment of $\mathrm{Fe}_{3} \mathrm{O}_{4}$ and its effect on the magnetic and wear properties of $\mathrm{Fe} 3 \mathrm{O} 4 /$ epoxy nanocomposites. Applied Surface Science. 2010; 256(23):69456950. http://dx.doi.org/10.1016/j.apsusc.2010.04.110.

56. Yu LG, Yamaguchi ES, Kasrai M and Bancroft GM. Study of silane-based antiwear additives: wear and chemistry. Tribology International. 2010; 44(6):692-701. http://dx.doi.org/10.1016/j. triboint.2010.03.005.

57. Hanetho SM, Kaus I, Bouzga A, Simon C, Grande T and Einarsrud M-A. Synthesis and characterization of hybrid aminopropyl silane-based coatings on stainless steel substrates. Surface and Coatings Technology. 2013; 238:1-8. http://dx.doi. org/10.1016/j.surfcoat.2013.10.013. 